OAK RIDGE
$\frac{\text { NATIONAL LABORATORY }}{\text { MANAGED BY UT-BATTELLE }}$
FOR THE DEPARTMENT OF ENERGY
ORNL/TM-2000/97

J. A. Shonder

\title{
A New Method to Determine the Thermal Properties of Soil Formations from In Situ Field Tests
}

\author{
J. V. Beck
}




\section{DOCUMENT AVAILABILITY}

Reports produced after January 1, 1996, are generally available free via the U.S. Department of Energy (DOE) Information Bridge:

Web site http://www.osti.gov/bridge

Reports produced before January 1, 1996, may be purchased by members of the public from the following source:

National Technical Information Service

5285 Port Royal Road

Springfield, VA 22161

Telephone 703-605-6000 (1-800-553-6847)

TDD 703-487-4639

Fax 703-605-6900

E-mailinfo@ntis.fedworld.gov

Web site http://www.ntis.gov/support/ordernowabout.htm

Reports are available to DOE employees, DOE contractors, Energy Technology Data Exchange (ETDE) representatives, and International Nuclear Information System (INIS) representatives from the following source:

Office of Scientific and Technical Information

P.O. Box 62

Oak Ridge, TN 37831

Telephone 865-576-8401

Fax 865-576-5728

E-mail reports@adonis.osti.gov

Web site http://www.osti.gov/contact.html

This report was prepared as an account of work sponsored by an agency of the United States Government. Neither the United States Government nor any agency thereof, nor any of their employees, makes any warranty, express or implied, or assumes any legal liability or responsibility for the accuracy, completeness, or usefulness of any information, apparatus, product, or process disclosed, or represents that its use would not infringe privately owned rights. Reference herein to any specific commercial product, process, or service by trade name, trademark, manufacturer, or otherwise, does not necessarily constitute or imply its endorsement, recommendation, or favoring by the United States Government or any agency thereof. The views and opinions of authors expressed herein do not necessarily state or reflect those of the United States Government or any agency thereof. 
ORNL/TM-2000/97

\title{
A New Method to Determine the Thermal Properties of Soil Formations from In Situ Field Tests
}

\author{
J. A. Shonder \\ Energy Division, Oak Ridge National Laboratory \\ J. V. Beck \\ Professor Emeritus, Michigan State University
}

April 2000

Prepared by

OAK RIDGE NATIONAL LABORATORY

Oak Ridge, Tennessee 37831-6285

managed by

UT-BATTELLE, LLC

for the

U.S. DEPARTMENT OF ENERGY

under contract DE-AC05-00OR22725 


\section{CONTENTS}

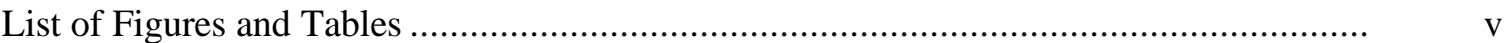

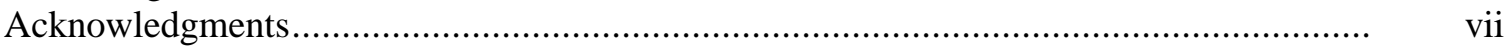

Abbreviations and Symbols ......................................................................................... ix

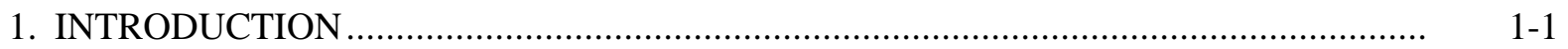

2. A NEW METHOD FOR DETERMINING SOIL THERMAL PROPERTIES ..................

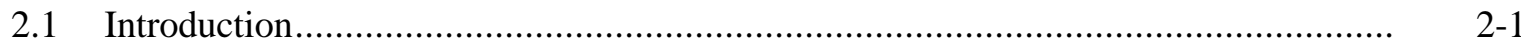

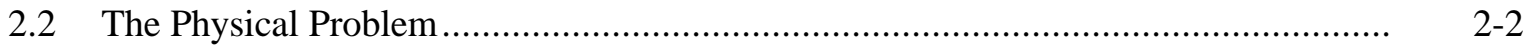

$2.3 \quad$ Energy Fluid Model...........................................................................................

2.4 Energy Model for Soil, Grout, and Film...............................................................

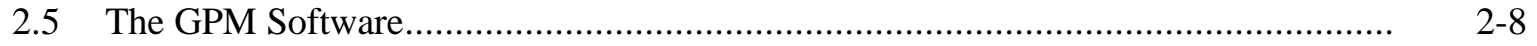

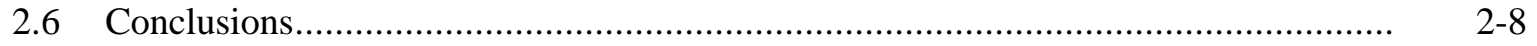

3. FIELD TESTS OF THE GPM SOFTWARE .................................................................

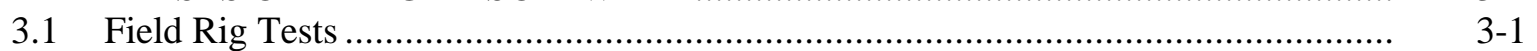

3.2 In Situ Tests at Two Elementary Schools .......................................................

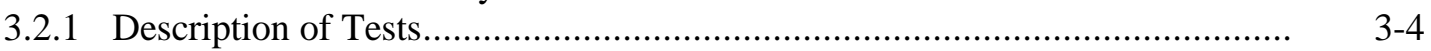

3.2.2 Test Results.................................................................................

3.2.3 Comparison with Other Analysis Techniques.......................................... 3-9

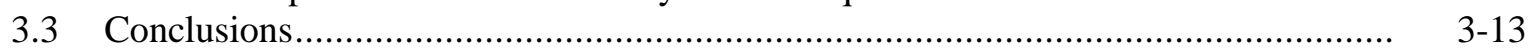

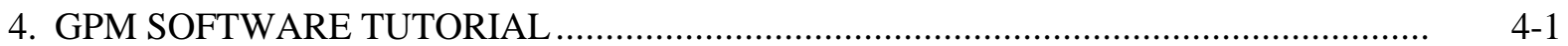

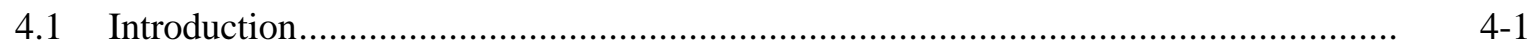

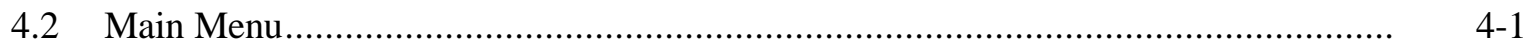

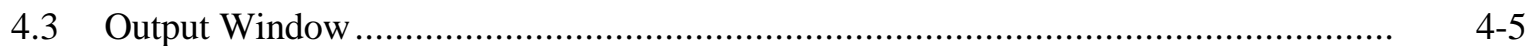

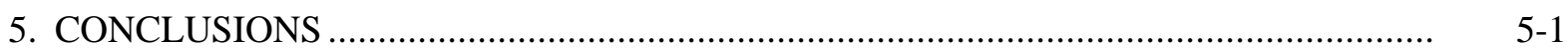

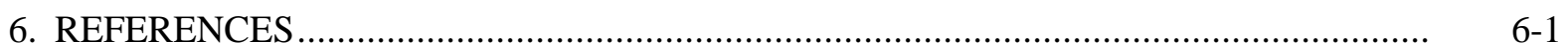




\section{FIGURES AND TABLES}

\section{Figures}

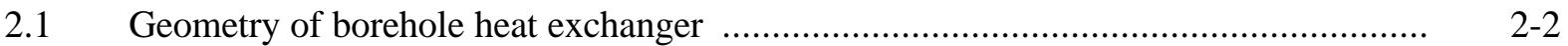

2.2 Control volume for thermal analysis of borehole heat exchanger ............................. 2-3

3.1 Measured and predicted average water temperature for experiment using the Oklahoma State University test rig ......................................................... 3-2

3.2 Residuals for the experiment on the Oklahoma State University test rig ................... 3-2

3.3 Sequential estimates of sand and grout thermal conductivity .................................... $3-4$

3.4 Power input and average water temperature, Campbell Elementary

School test \#1

3.5 Power input and average water temperature, Campbell Elementary

School test \#2

3.6 Power input and average water temperature, Maxey Elementary

3.7 Model error for Campbell Elementary School test \#1 ...........................................

3.8 Model error for Campbell Elementary School test \#2 …........................................... 3-8

3.9 Model error for Maxey Elementary School test \#1 ............................................. 3-8

3.10 Sequential thermal conductivity estimates, Campbell Elementary School test \#1 ....... 3-11

3.11 Sequential thermal conductivity estimates, Campbell Elementary School test \#2 ....... 3-11

3.12 Sequential thermal conductivity estimates, Maxey Elementary School test \#1 …...... 3-12

3.13 Temperature and power input vs time for a case in which the generator developed mechanical problems .............................................................................. $\quad 3-12$

3.14 Sequential thermal conductivity estimates from the data of Fig. 3.13 ....................... 3-13

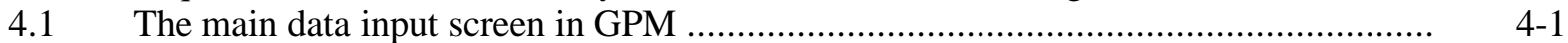

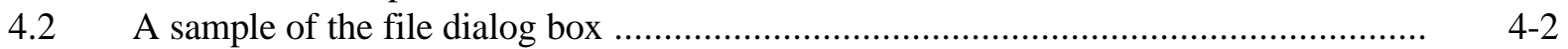

4.3 Cross-sectional view of borehole showing dimensions .............................................

4.4 The GPM output window .............................................................................

\section{Tables}

3.1 Parameters of three in situ thermal properties tests performed at Lincoln,

Nebraska, elementary schools

3.2 Results of soil thermal conductivity and borehole resistance estimates

from three in situ tests

3.3 Thermal conductivity estimates derived by three test methods from 50-h tests 


\section{ACKNOWLEDGMENTS}

The authors would like to express their appreciation to the following individuals and institutions for their support and collaboration in this work: Lew Pratsch of the U.S. Department of Energy;

Larry Hennings, Tim Pratt, Patrick Decker, Julie Kleager, and Brent Adams of the Lincoln Public

School District; Dr. Marvin Smith and Dr. Jeffrey Spitler of Oklahoma State University; and

Dr. Cenk Yavuzturk of the University of Wyoming. 


\title{
ABBREVIATIONS AND SYMBOLS
}

\author{
Abbreviations \\ BHEx borehole heat exchanger \\ Btu British thermal unit \\ $\mathrm{cfm}$ \\ CV \\ diam \\ cubic feet per minute \\ constant volume \\ EMS \\ GHP \\ diameter \\ GPM \\ h \\ energy management system \\ geothermal heat pump \\ Geothermal Properties Measurement (software) \\ hour \\ HVAC heating, ventilating, and air-conditioning \\ ORNL Oak Ridge National Laboratory \\ rms \\ root mean square \\ TMY typical meteorological year \\ VAV variable air volume
}

\section{Variables and Constants}

$a$ radius of $\mathrm{U}$-tube pipe

$b \quad$ radius of effective pipe

$c_{p} \quad$ specific heat

$k \quad$ thermal conductivity

$L \quad$ borehole length

$\dot{m} \quad$ flow rate

$q^{\prime} \quad$ rate of heat flow per unit length

$q^{\prime \prime} \quad$ rate of heat flow per unit area

$\hat{q}_{0} \quad$ rate at which heat is added to the fluid

$r$ radial variable

$r_{0} \quad$ borehole radius

$t$ time

$T$ temperature

$\bar{T} \quad$ average temperature

$\hat{T}$ measured temperature

$x \quad$ axial variable

$\alpha \quad$ thermal diffusivity

$\delta \quad$ film thickness

$\rho$ density

$\rho c_{p} \quad$ volumetric heat capacity

\section{Subscripts}

c cold or outlet side

$h$ hot or inlet side

$i$ time increment $\mathrm{i}$

$s \quad$ soil

$g \quad$ grout

$\phi \quad$ thin film

$\infty \quad$ infinity 


\section{INTRODUCTION}

The geothermal or ground-source heat pump (GHP) has been shown to be a very efficient method of providing heating and cooling for buildings. GHPs exchange (reject or extract) heat with the earth by way of circulating water, rather than by use of circulating outdoor air, as with an air-source heat pump. The temperature of water entering a GHP is generally cooler than that of outdoor air when space cooling is required, and warmer than that of outdoor air when space heating is required. Consequently, the temperature lift across a GHP is less than the lift across an air-source heat pump. The lower temperature lift leads to greater efficiency, higher capacity at extreme outdoor air temperatures, and better indoor humidity control. These benefits are achieved, however, at the cost of installing a ground heat exchanger. In general, this cost is proportional to length of the heat exchanger, and for this reason there is an incentive to install the minimum possible length such that design criteria are met.

The design of a ground heat exchanger for a GHP system requires, at a minimum, the operating characteristics of the heat pumps, estimates of annual and peak block loads for the building, and information about the properties of the heat exchanger: the size of the U-tubes, the grouting material, etc. The design also requires some knowledge of the thermal properties of the soil, namely thermal conductivity, thermal diffusivity, and undisturbed soil temperature. In the case of a vertical borehole heat exchanger (BHEx) these properties generally vary with depth; therefore, in the design, effective or average thermal properties over the length of the borehole are usually sought. When the cost of doing so can be justified, these properties are measured in an in situ experiment: a test well is drilled to a depth on the same order as the expected depth of the heat pump heat exchangers; a U-tube heat exchanger is inserted and the borehole is grouted according to applicable state and local regulations; water is heated and pumped through the U-tube (using a field generator to power the equipment, or line voltage where available); and the inlet and outlet water temperatures are measured as a function of time. Data on inlet and outlet temperature, power input to the heater and pump, and water flow rate are collected at regular intervals - typically 1 to $15 \mathrm{~min}$ - for the duration of the experiment, which may be as long as $60 \mathrm{~h}$.

Two common methods for determining soil thermal properties from such measurements are the line source method (Morgensen 1983) and the cylinder source method (Kavanaugh and Rafferty 1997). Both are based on long-term approximate solutions to the classical heat conduction problem of an infinitely long heat source in an infinite homogeneous medium. Although there are some differences in the way the two methods are implemented, the only difference between the two models is whether the heat source is considered to be a line or a cylinder. In both methods, power input to the water loop is assumed to be constant.

The simplicity of these methods makes them attractive, but they also have some disadvantages. First of all, because the line source and cylinder source approximations are inaccurate for early time behavior, some of the initial data from the field test must be discarded. The amount of data discarded can affect the property measurement. Also, both methods assume that the heat transfer to the ground loop is constant. In practice, heat input to the loop may vary significantly over the course of a field test due to rough operation of the generator or short-term sags and swells in power line voltage. Presumably, this variation affects the accuracy of the thermal property measurement, but error analysis is rarely performed.

This report presents a new method for determining thermal properties from short-term in situ tests using a parameter estimation technique. Because it is based on numerical solutions to the heat conduction equation, the new method is not affected by short-term variations in heat input. Also, 
since the model is accurate even for short times, there is no need to discard initial data. The parameter estimation technique used to determine the properties is based on statistical principles that provide quantitative estimates of measurement accuracy.

The parameter estimation method has now been tested with a laboratory test rig at Oklahoma State University and in field tests at two elementary schools in Lincoln, Nebraska. Using our estimation algorithms, and building on the validation achieved during testing, we have developed a computer program, the Geothermal Properties Measurement (GPM) model, that allows users to determine thermal properties from short-term in situ field tests. This program is currently available free of charge.

In Chapter 2 of this report, we describe the parameter estimation method and discuss the theory behind this method. Chapter 3 describes the test rig experiment and the field tests to validate the method. Chapter 4 provides a tutorial for the GPM software. 


\section{A NEW METHOD FOR DETERMINING SOIL THERMAL PROPERTIES}

\subsection{INTRODUCTION}

As noted in Chapter 1, two common methods for determining soil thermal properties from in situ field tests are the line source method and the cylinder source method. Both are based on analytical solutions to the classical heat conduction problem of an infinitely long heat source in an infinite homogeneous medium.

The line source method is based on classical theory, according to which, at sufficiently large times, the ground heat exchanger can be modeled as a line heat source in an infinite medium (Carslaw and Jaeger 1947; Ingersoll, Zobal, and Ingersoll 1954). Given the rate of heat input to the loop and the inlet and outlet temperatures as a function of time, the effective thermal conductivity of the soil formation can be determined. A problem with this method, however, is that it assumes the rate of heat input to the water loop to be constant. This is rarely the case, since in the field the heater is usually powered by a portable generator. Even where line electrical service is available, short-term sags and swells in voltage may cause variations in heat input to the water loop. The random variation in power input - as well as random errors in the temperature measurements - presumably cause variations in the value of thermal conductivity obtained from a particular experiment, but the classical theory provides no information on the variance. Another area of uncertainty is when to begin measuring inlet and outlet temperatures and for how long the data should be collected - i.e., the period during which the line source model is valid.

In the cylinder source method, ground heat exchangers are modeled as a cylindrical, constant heat source in an infinite medium (Ingersoll, Zobal, and Ingersoll 1954). Deerman and Kavanaugh (1991) extended this model to account for variable heat flux, but in a manner not generally suitable for the analysis of short-term field data. Other authors (Eskilson 1987; Hellstrom 1991; Rottmayer, Beckmann, and Mitchell 1997; Austin 1998) have proposed more detailed two- and three-dimensional numerical models.

The method we describe in this report is based on a simple one-dimensional thermal model that describes the temperature field around the borehole. The inlet and outlet pipe flows are modeled as one, and a thin film may be added to account for the heat capacity of the pipes and the fluid. With this method, ground conductivity can be relatively accurately estimated even though the conditions at the borehole are uncertain.

Based on numerical solutions to the heat conduction equation in cylindrical coordinates, the parameter estimation method includes the effect of grout inside the borehole, allowing borehole resistance to be estimated in addition to soil thermal conductivity. This is significant because after soil thermal conductivity, borehole resistance is the most important parameter in the design of a vertical BHEx. In the absence of a method to measure borehole resistance, this parameter is usually calculated on the basis of the assumed thermal properties of the grout and U-tube piping, and the assumed spacing between the U-tube pipes (which some authors refer to as the shank spacing). Since the shank spacing is never accurately known once the U-tube goes into the ground, and the thermal properties of the grout are rarely measured on-site, a borehole resistance calculated in this manner may be very different from the actual value. Measuring borehole resistance at the site will reduce this uncertainty. 
Another benefit to the method we have developed is that because the heat conduction problem is solved numerically rather than analytically, it is not necessary to assume constant heat input to the water loop. The heat transfer model uses the field-measured power input data rather than an average value. This feature is particularly useful in situations where unstable voltage (either from the power line or from the output of a portable generator) causes the power input to the water loop to vary over time. Because the line source and cylinder source methods both assume constant power input, their estimates of soil thermal properties tend to be inaccurate when the power input varies significantly.

A further benefit to our method is that it provides statistical estimates of the confidence intervals for the parameters estimated. Other methods of determining effective thermal properties have traditionally reported only the parameter value itself, with no estimate of accuracy. Obviously, the accuracy of a particular parameter value determined from a field experiment depends upon the accuracy of the data collection equipment, the length of the experiment, and other factors. The model we propose uses a statistical technique to provide a quantitative estimate of the confidence interval for the parameters measured.

The remainder of this section describes the theory behind our method.

\subsection{THE PHYSICAL PROBLEM}

Because the ground is not homogeneous in composition or density, and is affected by the presence of moisture, ground thermal properties can vary significantly with depth. A cross-section of a borehole of radius $r_{0}$ is shown in Fig. 2.1. The inlet and outlet pipes have an inside radius of $a$ and are surrounded by grout to a radius $r_{0}$. The temperatures of the fluid in the inlet and outlet pipes are considered to be only a function of axial position, $x$. The temperature of the fluid in the pipes does change with time, but the time constant of the fluid is assumed to be much smaller than that for the heat conduction in the ground. Hence, the fluid heat transfer in the pipes is modeled in a steady-state manner; however, the heat capacity of the fluid is lumped into a "film" because the turbulent flow causes negligible radial temperature variation in the fluid. The temperature variations of the fluid in the axial direction are averaged so that the inlet and outlet temperatures appear.

The energy transferred from the borehole (or to the borehole) is absorbed by the surrounding ground, with most of the energy absorbed some distance away from the borehole. As the cooling (or heating) time increases, the thermally affected region becomes larger - that is, the temperature penetration increases with time. Moreover, as the distance from the borehole increases, the temperature distribution becomes one-dimensional. Since the thermally active region increases with time and becomes one-dimensional away from the centerline of the borehole, the temperature distribution at a large distance from the U-tube is similar to that which would be caused by a single pipe with an effective radius.

The two pipes in the borehole are encased in a grout whose thermal properties are generally different from

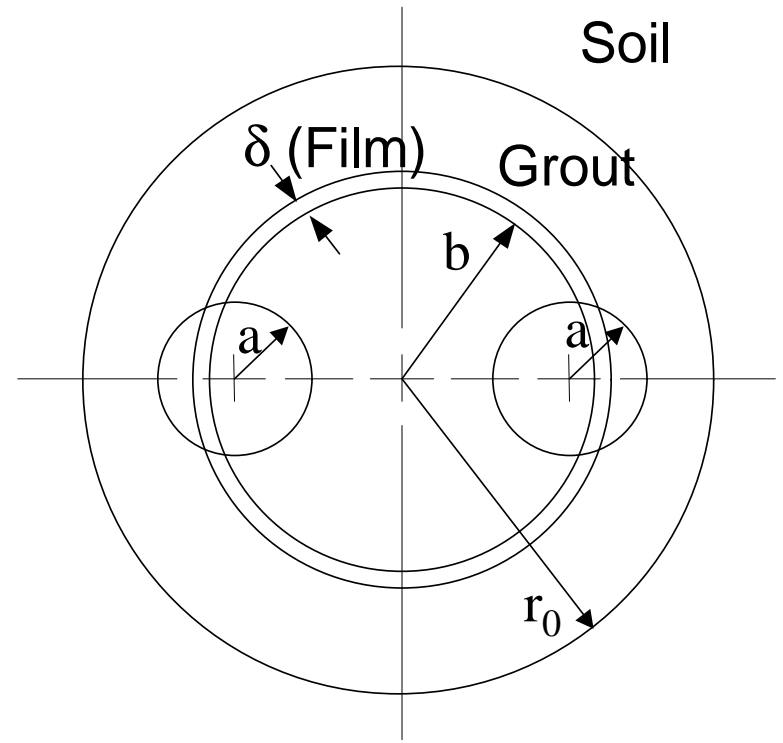

Fig. 2.1. Geometry of the borehole heat exchanger. 
the thermal properties of the surrounding ground. The spacing (also called the shank distance) of the two pipes is difficult to maintain in the $x$ direction, and the distances of the pipes from the edge of the borehole vary. The presence of the grout and the geometrical arrangement of the pipes is modeled by a single pipe of radius $b$. A thin film of thickness $\delta$ at the radius $b$ is included to incorporate the heat capacity of the fluid in the pipes and any differential heat capacity in the grout compared to that in the surrounding ground. The film's heat capacity is an additional parameters that can be estimated along with the ground thermal conductivity.

Without loss of generality but for simplicity in thinking, the inlet pipe is assumed to have hot fluid entering it at a mass flow rate of $m=\rho V A, \mathrm{~kg} / \mathrm{s}$, where $\rho$ is density, $V$ is fluid velocity and $A$ is the cross-sectional area of a pipe, $\pi a^{2}$. See Figs. 2.1 and 2.2. The heat flux $q_{h}(x, t), \mathrm{W} / \mathrm{m}^{2}$, is leaving the hot fluid and entering the surroundings. The other pipe is assumed to have the same fluid flow rate leaving and to be heated with a heat flux $q_{c}(x, t)$.

In the following sections we will first consider the fluid model based on an overall thermal control volume, and then the heat conduction in the ground.

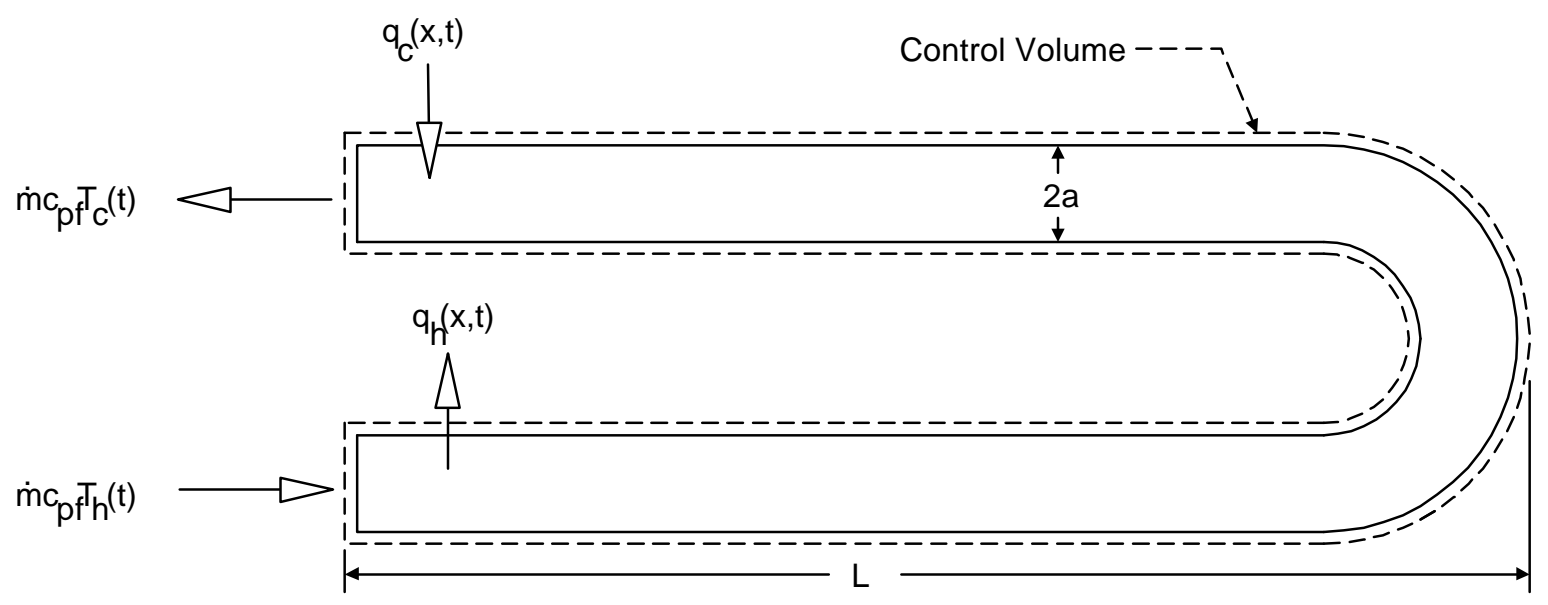

Fig. 2.2. Control volume for thermal analysis of borehole heat exchanger.

\subsection{ENERGY FLUID MODEL}

An energy balance on the fluid for the total length and for both pipes (see Fig. 2.2) gives

$$
m c_{p f}\left[T_{h}(0, t)-T_{c}(0, t)\right]=\int_{x=0}^{L}\left[q_{h}(x, t)-q_{c}(x, t)\right] P d x=0
$$

The inflow hot fluid temperature, $T_{h}(x, t)$, and the outflow cold fluid temperature, $T_{c}(x, t)$, are functions of time, but the rate of energy stored in the fluid is not included in Eq. (2.1). Energy absorbed by the fluid is lumped into an effective heat capacity of a thin film at the effective radius, $b$. The symbol $P$ denotes the effective pipe perimeter; $q_{h}(x, t)$ and $q_{c}(x, t)$ are the hot and cold side heat flux, respectively, and $c_{p f}$ is the specific heat of the fluid.

Because Eq. (2.1) does not account for the heat stored by the fluid and the pipes, it is accurate only for steady-state conditions; however, since the time constant for the fluid is assumed to be much 
shorter than that of the surrounding soil, modeling the fluid heat transfer as a steady-state process should not introduce large errors. As shown below, the heat stored by the fluid and piping will be included in another manner.

In the grout and the soil, heat transfer takes place through conduction. The energy transferred from the U-tube is absorbed by the grout and eventually by the surrounding soil. As the heating (or cooling) time increases, the thermally affected region becomes larger-that is, the thermal penetration increases with time. Moreover, as the distance from the borehole increases, the temperature distribution becomes one-dimensional in the $r$-direction. This suggests that the temperature distribution in the soil at a large distance from the U-tube is similar to that which would be caused by a single pipe with some effective radius. Thus, in the model developed below, the two pipes of the U-tube are replaced by a single pipe with an effective radius, as shown in Fig. 2.1

\subsection{ENERGY MODEL FOR SOIL, GROUT, AND FILM}

The one-dimensional model for heat transfer in the soil is the transient heat conduction equation. One equation is required for the thermal resistive film, another for the grout, and another for the surrounding soil. The model for the soil is

$$
\frac{k_{s}}{r} \frac{\partial}{\partial r}\left(r \frac{\partial T_{s}}{\partial r}\right)=(\rho c)_{s} \frac{\partial T_{s}}{\partial t}, r_{0}<r<\infty
$$

where the subscript $s$ denotes soil.

The grout is considered to extend from $b+\delta$ to $r_{0}$. The energy equation for the grout is similar to Eq. (2.2) with $s$ replaced by $g$ for grout,

$$
\frac{k_{g}}{r} \frac{\partial}{\partial r}\left(r \frac{\partial T_{g}}{\partial r}\right)=(\rho c)_{g} \frac{\partial T_{g}}{\partial t}, b+\delta<r<r_{0}
$$

Finally, a similar equation is written for the film, which extends from $b$ to $b+\delta$ :

$$
\frac{k_{t}}{r} \frac{\partial}{\partial r}\left(r \frac{\partial T_{t}}{\partial r}\right)=(\rho c)_{t} \frac{\partial T_{t}}{\partial t}, b<r<b+\delta
$$

where the subscript $t$ denotes the thin film. The radius $b$ is the effective radius, which is used to lump both pipes into one in the analysis. In Eqs. (2.2), (2.3), and (2.4) the temperature is a function of $r, x$, and $t$ but the heat conduction in the $x$ direction is assumed to be negligible compared to that in the $r$ direction. Hence, the net heat conduction term in the $x$ direction, $k \partial^{2} T / \partial x^{2}$, is not included in these equations.

The boundary condition at the effective pipe radius (where the film of thickness, $\delta$, is located) is

$$
-k_{t} \frac{\partial T_{t}(b, x, t)}{\partial r}=q_{h}(x, t)-q_{c}(x, t)
$$


which applies at each $x$; however, it is more convenient to average over $x$ in Eq. (2.5) and also in Eqs. (2.2), (2.3), and (2.4). Integrating Eq. (2.5) from $x=0$ to $L$ gives

$$
-k_{t} \frac{\partial \bar{T}_{t}(b, t)}{\partial r}=\frac{1}{L} \int_{x=0}^{L}\left(q_{h}(x, t)-q_{c}(x, t)\right) d x
$$

where

$$
\bar{T}_{t}(b, t)=\frac{1}{L} \int_{x=0}^{L} T_{t}(b, x, t) d x
$$

The differential equations for the conduction in the soil, grout, and film are now averaged over $x$ from 0 to $L$. Equations (2.2), (2.3), and (2.4) become

$$
\begin{gathered}
\frac{k_{s}}{r} \frac{\partial}{\partial r}\left(r \frac{\partial \bar{T}_{s}}{\partial r}\right)=(\rho c)_{s} \frac{\partial \bar{T}_{s}}{\partial t}, r_{0}<r<\infty \\
\frac{k_{g}}{r} \frac{\partial}{\partial r}\left(r \frac{\partial \bar{T}_{g}}{\partial r}\right)=(\rho c)_{g} \frac{\partial \bar{T}_{g}}{\partial t}, b+\delta<r<r_{0} \\
\frac{k_{t}}{r} \frac{\partial}{\partial r}\left(r \frac{\partial \bar{T}_{t}}{\partial r}\right)=(\rho c)_{t} \frac{\partial \bar{T}_{t}}{\partial t}, b<r<b+\delta
\end{gathered}
$$

where the average temperatures are defined by

$$
\begin{aligned}
& \bar{T}_{s}(r, t)=\frac{1}{L} \int_{x=0}^{L} T_{s}(r, x, t) d x, \\
& \bar{T}_{g}(r, t)=\frac{1}{L} \int_{x=0}^{L} T_{g}(r, x, t) d x, \\
& \bar{T}_{t}(r, t)=\frac{1}{L} \int_{x=0}^{L} T_{t}(r, x, t) d x .
\end{aligned}
$$

A complete mathematical statement is then Eqs. (2.8), (2.9), and (2.10) with the boundary condition at $r=b$ given by Eq. (2.6) and the interface conditions given by

$$
\begin{gathered}
k_{t} \frac{\partial \bar{T}_{t}(b+\delta, t)}{\partial r}=k_{g} \frac{\partial \bar{T}_{g}(b+\delta, t)}{\partial r}, \\
\bar{T}_{t}(b+\delta, t)=\bar{T}_{g}(b+\delta, t), \\
k_{g} \frac{\partial \bar{T}_{g}\left(r_{0}, t\right)}{\partial r}=k_{s} \frac{\partial \bar{T}_{s}\left(r_{0}, t\right)}{\partial r},
\end{gathered}
$$




$$
\bar{T}_{g}\left(r_{0}, t\right)=\bar{T}_{s}\left(r_{0}, t\right)
$$

The boundary condition given by Eq. (2.6) can also be related to the input and output fluid temperatures to get the alternate boundary condition,

$$
-k_{t} \frac{\partial \bar{T}_{t}(b, t)}{\partial r}=\frac{m c_{p f}}{P L}\left[T_{h}(0, t)-T_{c}(0, t)\right]
$$

The boundary condition at $r=\infty$ is

$$
\bar{T}_{s}(\infty, t)=T_{\infty}
$$

and the initial conditions are

$$
\bar{T}_{s}(r, 0)=T_{\infty}, \bar{T}_{t}(r, 0)=T_{\infty}, \bar{T}_{g}(r, t)=T_{\infty}
$$

The ratio $m c_{p f} / P L$ in Eq. (2.13) is also equal to

$$
\frac{m c_{p f}}{P L}=\frac{G \pi a^{2} c_{p f}}{2 \pi b L}=\frac{G a^{2} c_{p f}}{2 b L},
$$

where $G$ is the mass flux in $\mathrm{kg} / \mathrm{m}^{2}$-s.

The boundary condition given by Eq. (2.18) can also be written as

$$
-k_{t} \frac{\partial \overline{T_{t}}(b, t)}{\partial r}=q_{0}(t)
$$

where the heat flux $q_{0}(t)$ is the field-measured heat flux divided by the borehole depth $L$.

In summary, the direct problem is described by Eqs. (2.8), (2.9), and (2.10) with interface conditions, Eqs. (2.14) through (2.17); the condition at infinity, Eq. (2.19); and initial conditions, Eq. (2.20). The boundary condition at $r=b$ is Eq. (2.22).

The equations above are a complete mathematical statement of the direct problem. However, the problem cannot be solved with classical techniques because not all of the relevant parameters (such as the ground and film thermal conductivities) are known. Some extra information is available that allow these and other parameters to be estimated. The average fluid temperature, defined by the average of the inlet and outlet temperatures, is known:

$$
Y_{f}=\left(T_{h}(t)+T_{c}(t)\right) / 2
$$

This average temperature may not be precisely equal to the integrated averages of the inlet and outlet fluid temperatures but is expected to be as accurate as the lumping of the two pipes into one.

Furthermore, the inlet and outlet temperatures are the only temperatures that are measured. This temperature is equal to the average of the surface film temperature given by Eq. (2.6). Hence, two conditions are given at the film surface: heat flux and temperature histories. For direct problems only 
one condition can be used; thus, there is excess information. This information is used to estimate one or more parameters in a least squares sense. The $Y$ symbol is used in Eq. (2.19) to denote a measured quantity.

The calculated average surface temperature history given by Eq. (2.6) is made to agree in a least squares sense with the measured average fluid temperature given by Eq. (2.19) by minimizing a sum of squares function with respect to parameters, such as the ground thermal conductivity. The sum of square function, $S$, is

$$
S=\sum_{i=1}^{n}\left(Y_{i}-T_{t, i}\right)^{2}
$$

where $i$ denotes a measurement time, $Y_{i}$ the average fluid temperature, and $T_{t, i}$ the average temperature of the film at $r=b$.

Note that if the film thickness is taken to be zero, if the film is assumed to have no volumetric heat capacity and no resistance to heat transfer, and if the grout has the same thermal properties as the soil, then the problem reduces to that of a cylindrical heat source in an infinite medium. For constant heat flux, this problem has an analytical solution involving a rather complicated integral of Bessel and other functions (Ingersoll, Zobal, and Ingersoll, 1954). The method can be extended to the case of non-constant heat flux using a convolution process, but this is difficult to implement numerically. For this reason, and so that the effect of the thin film and the grout can be included, we solve the direct problem numerically using a finite difference grid and a Crank-Nicolson integration scheme.

Altogether, the model presented above contains nine parameters: the thermal conductivities of the soil, grout, and thermal film; the volumetric heat capacities of the soil, grout, and thermal film,; the thickness of the thermal film; the effective pipe radius, and the far-field temperature. In general, however, it will not be possible to estimate all of these parameters with a single experiment, as some may be dependent on others. For example, since the thin film is used to account for the thermal capacitance of the fluid and pipes, we would expect the thickness, $\delta$, to be related to the film's volumetric heat capacity.

The parameter estimation algorithm proceeds by first assuming trial values for the parameters in question. Given these values, the (measured) heat flux is used to drive the numerical model. The numerical model gives a predicted value of $T_{t}$ as a function of time for the duration of the experiment. The sum of squared errors between the predicted and measured temperatures are calculated as in Eq. (2.20). The Gauss method of minimization is then used to determine the parameter values that minimize the sum of the squared errors.

While the derivation is beyond the scope of this report, use of the Gauss minimization technique enables calculation of approximate confidence regions for the parameters (Beck and Arnold 1977). The validity of these confidence intervals depends on a number of statistical assumptions that may or may not be satisfied in a given experiment. A number of other sources of error are unaccounted for by these confidence intervals: the assumption that the soil properties are homogeneous, when in fact they vary with depth; the assumption that the far-field temperature, $T_{\infty}$, is accurately measured; and of course, the assumption that a rather complicated three-dimensional heat transfer process can be represented by a one-dimensional model. For this reason we expect the confidence intervals derived from the data to be somewhat smaller than the true confidence intervals; the true confidence intervals on the parameter estimates may be as much as twice the value indicated. Nevertheless, these 
approximate confidence intervals are useful for qualitative assessment of the accuracy of property values and for comparing one experiment to another.

\subsection{THE GPM SOFTWARE}

The method described above has been incorporated into a stand-alone software program called GPM (geothermal properties measurement). The program requires as input a text file containing average fluid temperature (i.e., the average between U-tube inlet and outlet temperatures) and heat input at constant time intervals. This data is usually measured in a short-term in situ field test. The program uses parameter estimation techniques to determine the soil formation thermal properties that best match the data.

As indicated in Section 2.4, the model described above includes no fewer than nine parameters that could potentially be determined by way of parameter estimation: the thermal conductivities of the soil, grout, and thermal film; the volumetric heat capacities of the soil, grout, and thermal film; the thickness of the thermal film; the effective pipe radius; and the far-field temperature. In general, however, it is not possible to estimate all of these parameters with a single experiment. The GPM program provides the option to determine $(a)$ soil thermal conductivity and far-field temperature or (b) soil thermal conductivity, borehole resistance, and far-field temperature. Chapter 3 presents the results of a validation study of the GPM software, and Chapter 4 provides a brief user's manual.

\subsection{CONCLUSIONS}

The one-dimensional parameter estimation model describes the thermal behavior of a borehole heat exchanger for a GHP. The model lumps the inlet and outlet pipes into one pipe of an effective radius $b$ and adds a film at the outer surface of the pipe to account for the heat transfer resistance of the surrounding grout and the convective heat transfer coefficient. The film also has an effective heat capacity to model the heat capacity of the fluid and the different heat capacity of the grout compared to the ground. Parameter estimation techniques are used to derive values of soil and grout thermal conductivity from the model and experimental data. An important feature of this technique is that it provides approximate confidence intervals on the parameter estimates; these intervals can be used to assess the accuracy of experiments and the thermal conductivities derived from such experiments. 


\section{FIELD TESTS OF THE GPM SOFTWARE}

\subsection{FIELD RIG TESTS}

A major problem in validating a model such as the one presented in Chapter 2 is that the true soil formation thermal properties at a given site are generally unknown. Where estimates of these properties are available, they are usually based on previous experiments and other simplified heat transfer models such as the line heat source. Recently, however, a test rig was constructed at Oklahoma State University to simulate the conditions in which a vertical heat exchanger operates. The rig consists of a box made of $3 / 4-i n$. plywood, with approximate dimensions of $4 \times 4 \times 48 \mathrm{ft}$. A U-tube heat exchanger consisting of nominal 1-in.-diam polyethylene piping is placed horizontally along the centerline of the box, parallel to the long axis. The U-tube is grouted to a diameter of 5 in. from the centerline, and the box is filled with a homogeneous material with known thermal conductivity. As in a field experiment, water is heated and pumped through the U-tube at a known flow rate while the rate of heat input and inlet and outlet water temperatures are measured at regular intervals. Although we recognize that this rig does not exactly duplicate the heat transfer processes that take place in a vertical heat exchanger in a field installation, it does provide an opportunity to build confidence in heat transfer models such as the one we have developed, since the material which represents the soil is homogeneous, and its thermal conductivity can be measured independently.

A data set from a 63-h experiment was obtained from Dr. Marvin Smith (personal communication from M. Smith, Oklahoma State University, to J. Shonder, March 1998). For the experiment the rig was filled with wet sand, and the U-tube was grouted with a commercially available grout. The thermal conductivity of the sand was measured twice using a thermal probe, giving values of 1.40 and $1.45 \mathrm{Btu} / \mathrm{hr}-\mathrm{ft}-{ }^{\circ} \mathrm{F}$. At the beginning of the experiment the sand was at a uniform temperature of $72.0^{\circ} \mathrm{F}$. During the experiment, the average flow rate of water was approximately $4 \mathrm{gal} / \mathrm{min}$, and the average rate of heat input was $363 \mathrm{~W}$. Both of these values varied by only about $\pm 0.5 \%$ of their average values over the 63 -h period. Water inlet and outlet temperature, flow rate, and power to the heater were measured at 1-min intervals.

To analyze the experimental data, some modifications were made to the model to account for the physical characteristics of the test rig. Since the model is radially symmetrical, the rig was modeled as a cylinder consisting of four regions with different materials. The U-tube was modeled as a single pipe with an effective diameter of 0.75 in. (A value of 0.5 in. was also used; as discussed below, the effective pipe diameter appears to have only a small effect on the thermal property estimates.) A thin film is assumed to exist at the surface of the pipe to simulate the heat capacity of the water and the pipes; the film is assumed to be 0.024 in. thick. The diameter of the grout is given as 5 in.; thus, the material from the outer edge of the thin film to a radius of $2.5 \mathrm{in}$. is assumed to be grout. The bulk of the region is the sand, from the outer radius of the grout to an effective radius of $2.246 \mathrm{ft}$. Plywood with a thickness of $0.75 \mathrm{in}$. is at the outer radius. To summarize, in the radial direction there is the film, grout, sand, and plywood. The finite difference model includes 72 nodes: 2 in the film, 6 in the grout, 60 in the sand, and 4 in the plywood. The internal time step was $15 \mathrm{~s}$. In the analysis, the outer boundary of the plywood is assumed to be isothermal at the initial temperature of $72.0^{\circ} \mathrm{F}$. A volumetric heat capacity of $35 \mathrm{Btu} / \mathrm{ft}^{3}-\mathrm{hr}$ was assumed for both the sand and the grout. The thermal conductivity of the film was assumed to be a large value; thus, all of the resistance to heat transfer is contained in the soil and the grout. Three parameters are estimated: the thermal conductivity of the soil, the thermal conductivity of the grout, and the volumetric heat capacity of the thin film. 
Fig. 3.1 plots the measured average water temperature and the model's predicted average temperature for the first $30 \mathrm{~h}$ of the experiment, at the converged values of the parameters. There is excellent agreement between the two. In order to distinguish between model and data, the predicted water temperature is plotted only at intervals of $1 \mathrm{~h}$. Figure 3.2 presents the residuals - i.e., the difference between the measured and predicted average water temperature - as a function of time for the first $30 \mathrm{~h}$. The larger residuals at early times are probably due to the assumption of one-dimensional heat transfer. However, since the largest residual is only $0.2^{\circ} \mathrm{F}$, the error is not large. Although the residuals are small overall, with a root mean square $(\mathrm{rms})$ value of $0.057^{\circ} \mathrm{F}$, if the model were truly an accurate representation of the heat transfer process taking place in the test rig, we would expect the residuals to be random and uncorrelated, which they clearly are not. Their slow rise and fall over the $30 \mathrm{~h}$ indicates that there may be some secondary effects which the model does not capture.

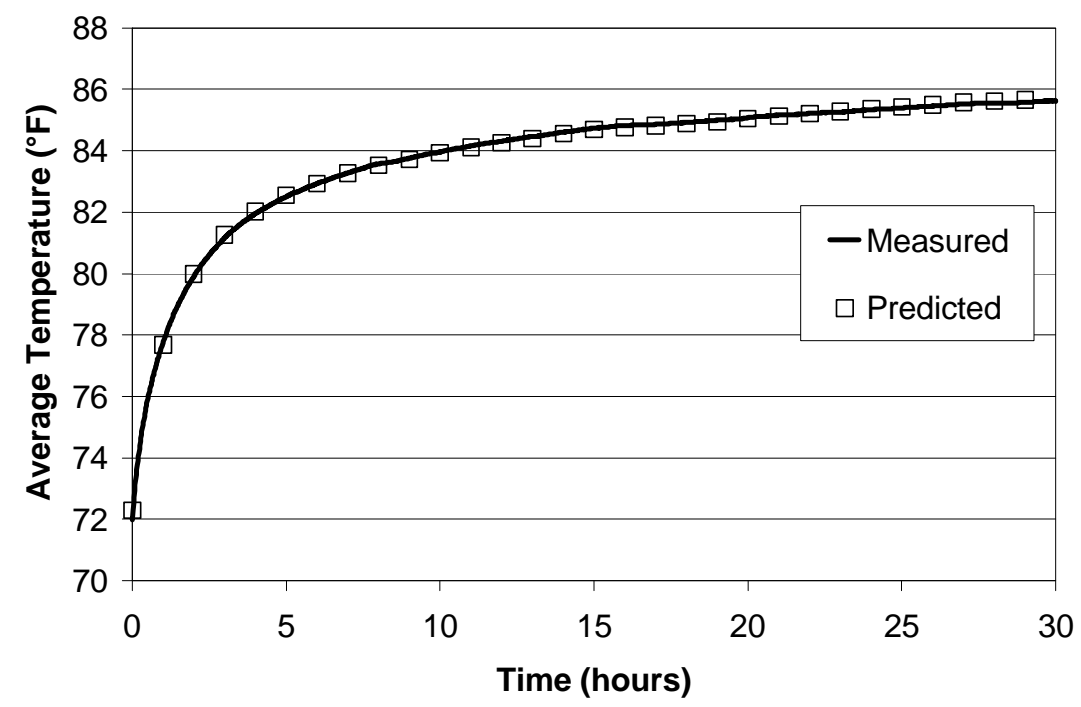

Fig. 3.1. Measured and predicted average water temperature for experiment using the Oklahoma State University test rig.

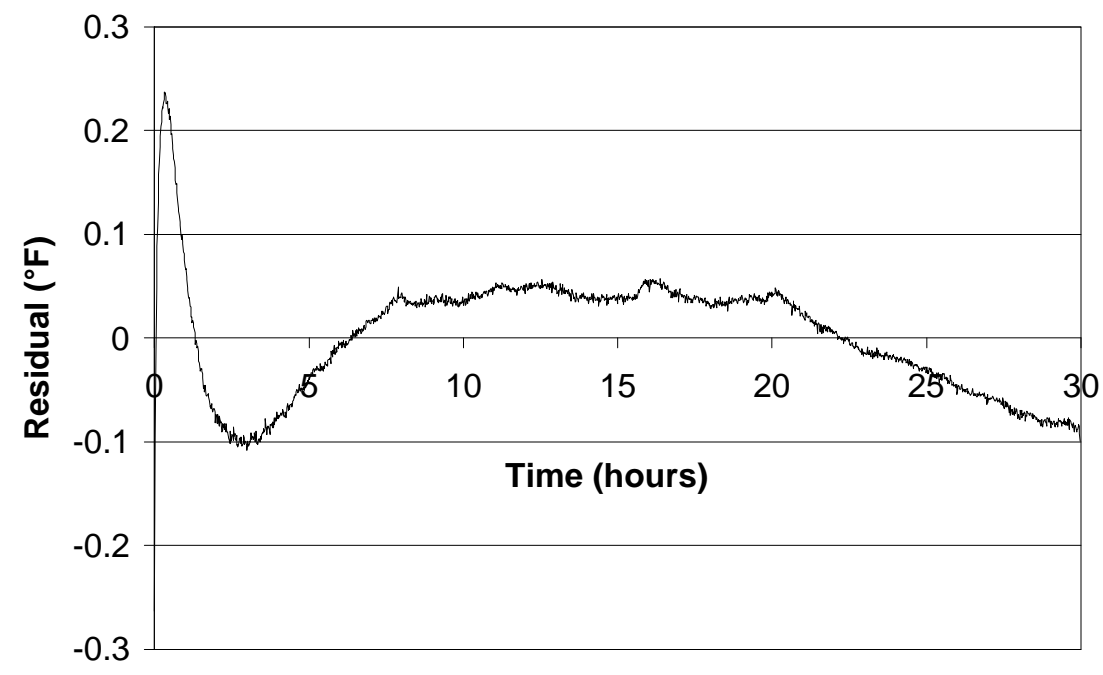

Fig. 3.2. Residuals for the experiment on the Oklahoma State University test rig. 
The estimate of thermal conductivity from the model is in excellent agreement with the measured values. After $30 \mathrm{~h}$ the converged value of thermal conductivity for the wet sand is $1.411 \mathrm{Btu} / \mathrm{hr}-\mathrm{ft}-{ }^{\circ} \mathrm{F}$, compared with the measured values of 1.40 and 1.45 . The $95 \%$ confidence region for the thermal conductivity value is $\pm 0.172 \mathrm{Btu} / \mathrm{hr}-\mathrm{ft}-{ }^{\circ} \mathrm{F}$, or about $12 \%$ of the estimated value.

The converged value for the thermal conductivity of the grout is $0.619 \mathrm{Btu} / \mathrm{hr}-\mathrm{ft}-{ }^{\circ} \mathrm{F}$ with a $95 \%$ confidence region of $0.037 \mathrm{Btu} / \mathrm{hr}-\mathrm{ft}-{ }^{\circ} \mathrm{F}$, which is about $6 \%$ of the estimated value. The actual thermal conductivity of the grout was not available, but the value of $0.619 \mathrm{Btu} / \mathrm{hr}-\mathrm{ft}-{ }^{\circ} \mathrm{F}$ is in the range of values reported in the literature. In any case, we expect that the estimated grout thermal conductivity accounts for other effects, such as the contact resistance between the pipes and the grout.

The time required to converge to a solution depends, of course, on the initial guesses for the parameter values. Nevertheless, even for guesses 50\% larger than the true values, the model requires only about $60 \mathrm{~s}$ to converge on a $200-\mathrm{MHz}$ PC.

We performed a second run assuming an effective pipe diameter of $0.5 \mathrm{in}$. In this case the converged value of the sand thermal conductivity was $1.421 \pm 0.133 \mathrm{Btu} / \mathrm{hr}-\mathrm{ft}-{ }^{\circ} \mathrm{F}$, which indicates that the effective pipe diameter has only a small effect on the thermal conductivity measurement. Bose, Parker, and McQuiston (1985) have recommended using an effective diameter of $\sqrt{2}$ times the diameter of the U-tube piping, which in this case would correspond to a radius of 0.707 . Since there was little difference between the thermal conductivity estimates using effective radii of 0.5 and 0.75 in., we would agree with the recommendation of these authors.

The thermal property estimates changed somewhat when data up to $60 \mathrm{~h}$ were used. With an effective pipe radius of $0.75 \mathrm{in}$., the rms value of the residuals increased slightly, to $0.064^{\circ} \mathrm{F}$. The converged value for the thermal conductivity for the sand increased to $1.558 \pm 0.118 \mathrm{Btu} / \mathrm{hr}-\mathrm{ft}-{ }^{\circ} \mathrm{F}$. This is higher than the value obtained after $30 \mathrm{~h}$, but the measured value of thermal conductivity still lies within the $95 \%$ confidence region. The converged value of the grout thermal conductivity was slightly lower in this case, $0.593 \pm 0.023 \mathrm{Btu} / \mathrm{hr}^{-\mathrm{ft}-}{ }^{\circ} \mathrm{F}$.

Sequential estimates of the sand and grout thermal conductivity are presented in Fig. 3.3. This figure shows, for each time, the values of the thermal conductivities estimated using all data up to and including that time. If the model were an accurate representation of the heat transfer processes taking place in the test rig, we would expect both curves to flatten out at later times. In the case of the grout thermal conductivity this does seem to occur; the estimate of the sand thermal conductivity appears to be rising slightly even at $60 \mathrm{~h}$. This may be due to the assumptions made in the analysis, primarily the assumption that the rectangular test rig could be modeled as a cylinder. We would expect errors associated with this assumption to become more important at later times. Of course, this would not be a concern in a field test.

\subsection{IN SITU TESTS AT TWO ELEMENTARY SCHOOLS}

The tests at Oklahoma State University showed that our method could predict the thermal conductivity of a known material (moist sand) accurately, given data collected in an experiment on a laboratory test rig. However, further work was needed to validate the model and gain experience in its use. We also wanted to estimate other parameters, especially borehole resistance (the total resistance of heat transfer from the fluid to the borehole wall), a parameter that is required by many design algorithms. Therefore, we set up a series of field experiments in which the model's thermal conductivity estimates would be compared with estimates from other commonly used models and 


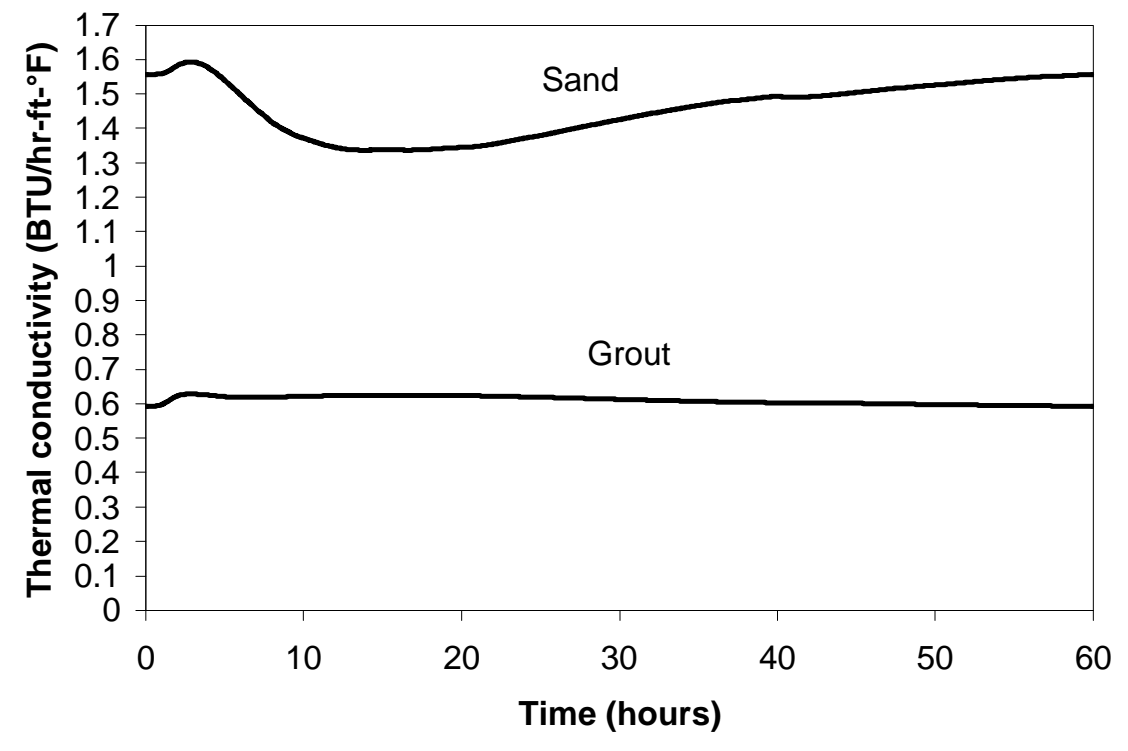

Fig. 3.3. Sequential estimates of sand and grout thermal conductivity.

with the "true" or effective thermal conductivity of the soil, determined from data on active borefields at the sites.

We conducted three in situ tests at two elementary schools, Maxey and Campbell, in Lincoln, Nebraska, in 1998 and 1999. Data from in situ field tests provide a more rigorous test of a properties measurement technique than data from laboratory experiments, but a field test has the drawback that the true thermal conductivity of the soil formation and borehole resistance at the site are generally unknown. For the Maxey School site, however, analysis of one year of data from the operating borefield provided an estimate for the effective soil thermal conductivity that could be compared with the measured values.

At Campbell Elementary School, two boreholes were drilled with the same diameter and the same approximate depth, about $60 \mathrm{ft}$ apart. A third borehole was drilled at Maxey. Three different grouts were used: thermal grout 85 , fine sand, and soil cuttings. The tests were blind in that the driller did not inform us of which grout was used in which borehole.

One objective of the in situ field tests was to determine whether the soil conductivity estimates for the two boreholes at Campbell agreed with each other and whether the conductivity estimate at Maxey agreed with the thermal conductivity estimate obtained from analysis of the operating data. Another objective was to determine whether the numerical method could identify the different borehole resistances resulting from the different grouts. Table 3.1 shows the parameters of the tests. For purposes of comparison, the three data sets were also analyzed using the line source and cylinder source methods.

\subsubsection{Description of Tests}

For each test, a 4.25-in. diameter borehole was drilled to an approximate depth of $245 \mathrm{ft}$. Nominal 1-in. SDR-11 U-tube pipe was inserted, and the boreholes were grouted with either thermal grout or 
Table 3.1. Parameters of three in situ thermal properties tests performed at Lincoln, Nebraska, elementary schools

\begin{tabular}{lcrrr}
\hline Test designation & $\begin{array}{l}\text { Date } \\
\text { performed }\end{array}$ & $\begin{array}{l}\text { Borehole } \\
\text { depth } \\
(\mathbf{f t})\end{array}$ & $\begin{array}{l}\text { Average soil } \\
\text { temperature } \\
\left({ }^{\circ} \mathbf{F}\right)\end{array}$ & \multicolumn{2}{l}{$\begin{array}{l}\text { Average power } \\
\text { input } \\
(\mathbf{W})\end{array}$} \\
\hline Maxey & $09 / 19 / 98$ & 245 & 55.7 & 2609 \\
Campbell \#1 & $09 / 15 / 98$ & 245 & 53.8 & 2595 \\
Campbell \#2 & $10 / 08 / 98$ & 244 & 55.6 & 2606 \\
\hline
\end{tabular}

fine sand, or not grouted at all. In general, the boreholes were drilled about $75 \mathrm{ft}$ from the active borefield. The two boreholes at Campbell school were approximately $60 \mathrm{ft}$ apart.

The equipment used to perform the in situ tests has been described by Austin (1998). Housed in a trailer that is towed to the site, the apparatus includes two circulating pumps, a flowmeter, and three in-line water heaters, all powered by a portable electric generator. A watt transducer measures the power consumption of the heaters and circulating pumps, and the inlet and outlet temperatures are measured using two high-accuracy thermistors immersed in the flow. The water flow rate, total power input, and inlet and outlet temperature were logged at 15-min intervals.

Before the U-tube was connected to the test apparatus, a thermistor was inserted into one end of the U-tube and the water temperature was measured at 10-ft intervals. The average undisturbed soil temperature at each site was assumed to be the average of these measurements. The actual length of the installed heat exchanger was also determined from these measurements.

Figures 3.4 and 3.5 present the power input and average water temperature as a function of time for the two experiments at Campbell School, and Fig. 3.6 presents the data for the experiment at Maxey School. The three tests are unremarkable except for the test on the second well at Campbell. Just noticeable in Fig. 3.5 are two jumps in average temperature at $27.5 \mathrm{~h}$ and at $33.5 \mathrm{~h}$. Beginning at

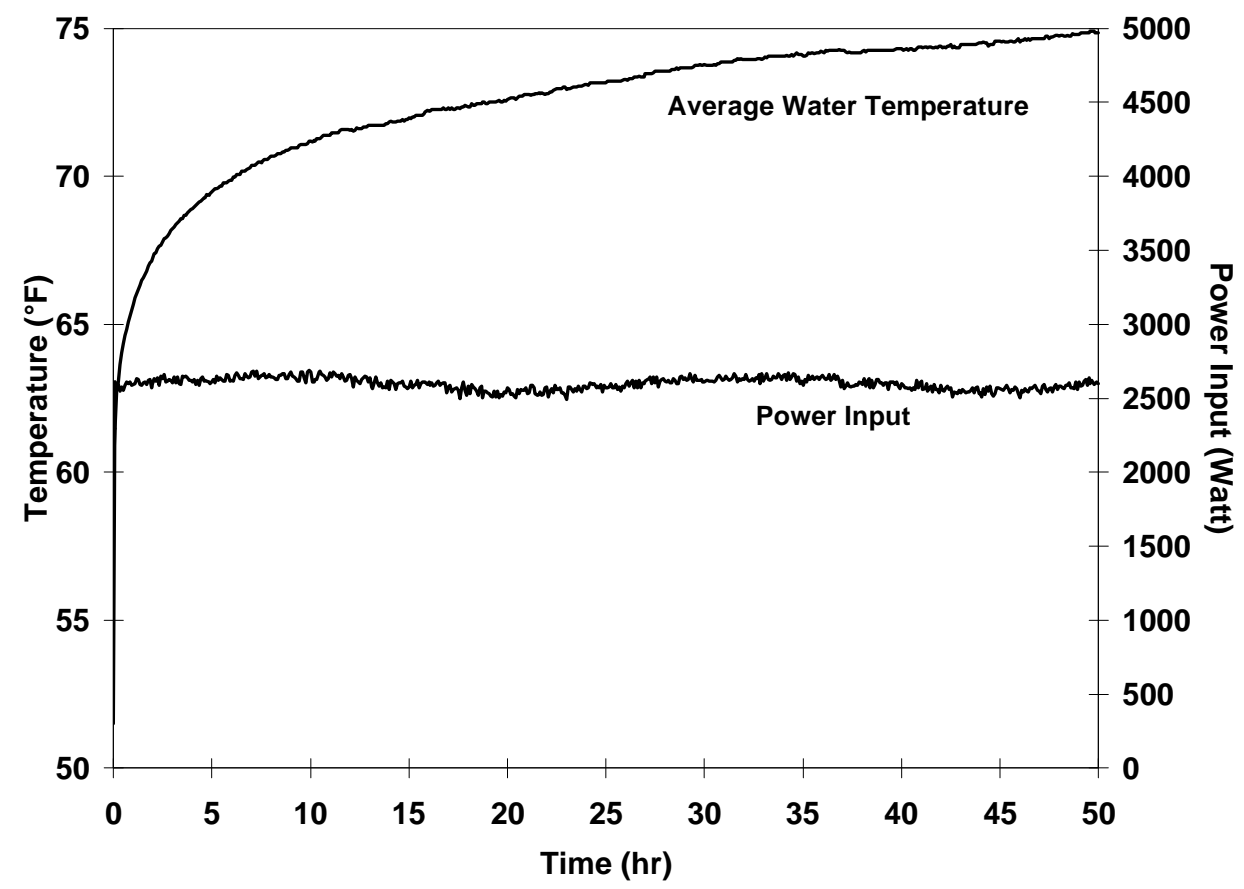

Fig. 3.4. Power input and average water temperature, Campbell Elementary School test \#1. 


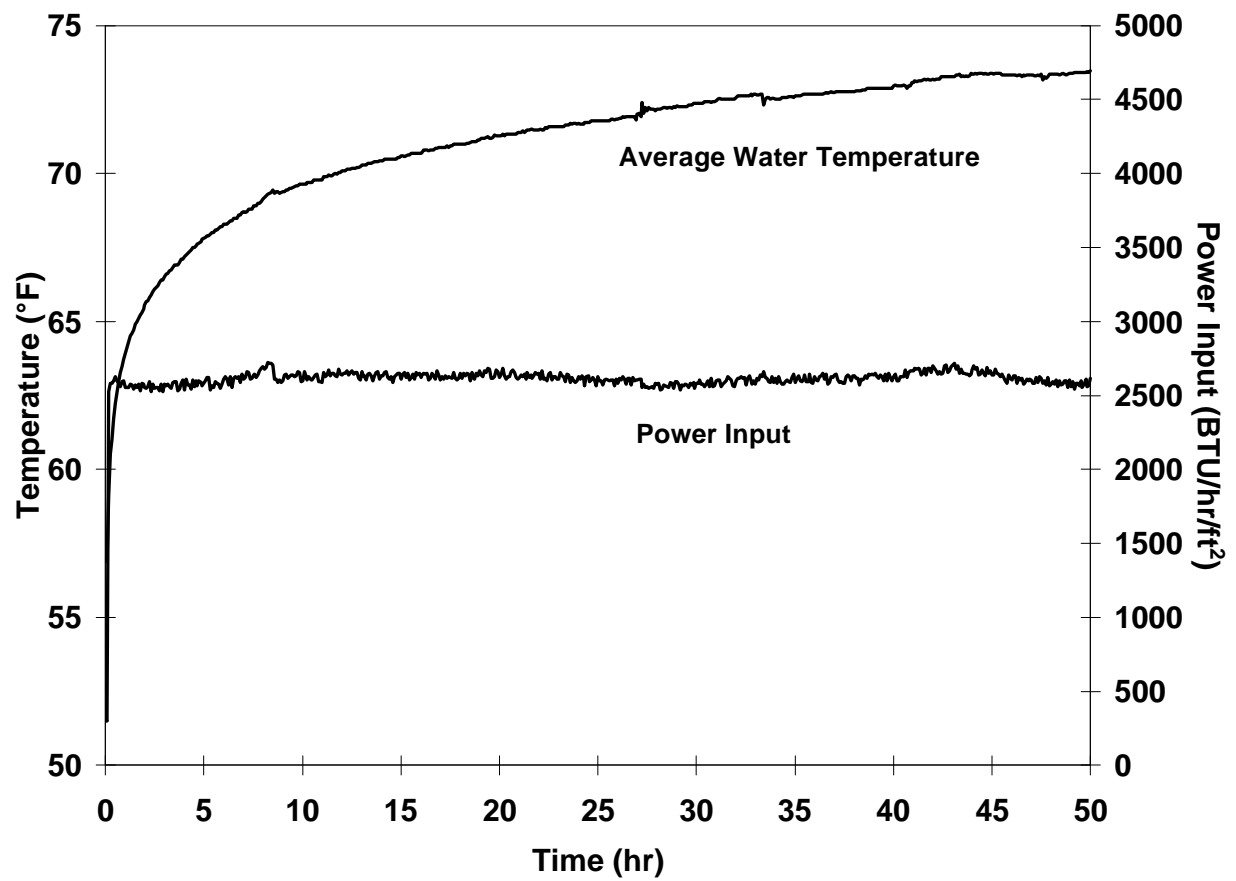

Fig. 3.5. Power input and average water temperature, Campbell Elementary School test \#2.

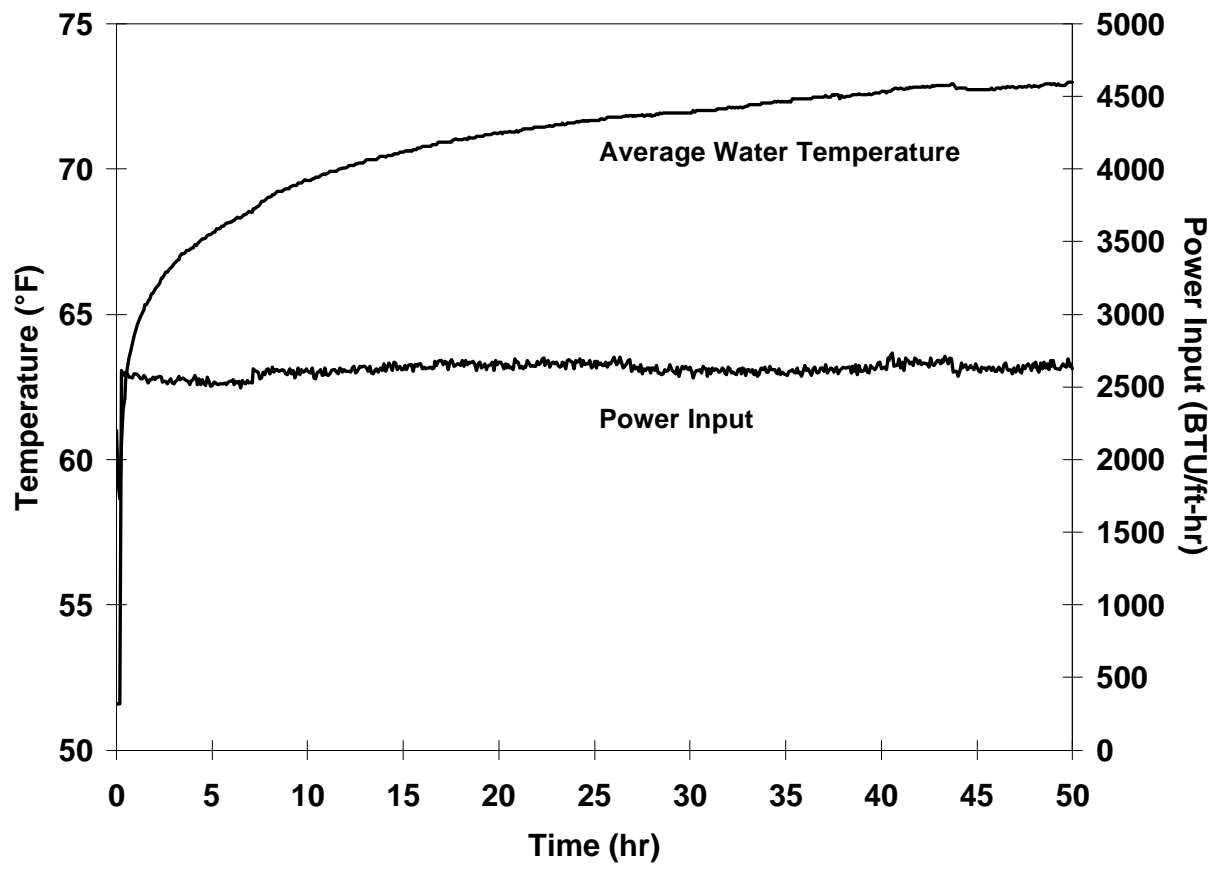

Fig. 3.6. Power input and average water temperature, Maxey Elementary School test \#1. 
$27.5 \mathrm{~h}$, the water flow rate through the heat exchanger dropped by about $15 \%$, possibly due to the presence of air in the heat exchanger. This does not appear to have affected the accuracy of the parameter estimates.

\subsubsection{Test Results}

One indication of a model's reliability is its ability to predict the temperature rise of the water as a function of time. Although the one-dimensional numerical model includes a number of simplifications, it is able to predict the average water temperature in the heat exchanger with good accuracy. Figures 3.7 through 3.9 present plots of the residuals between the measured and predicted average temperature as a function of time. For times after about $30 \mathrm{~min}$, the residuals are quite small, on the order of $0.17^{\circ} \mathrm{F}$. The model did not accurately follow the system behavior during the sharp decrease in flow rate that occurred during the second Campbell experiment, but again, this did not seem to affect the property estimates in that case.

\section{Thermal Conductivity}

Table 3.2 presents the estimates for soil thermal conductivity and borehole resistance. There is good agreement between the two thermal conductivity measurements at each site. The value of 1.36 obtained for the Maxey test agrees well with the value of 1.3 obtained from analysis of a year's operating data from the borefield (Thornton 1999). The average of the two Campbell measurements is 1.20 BTU/hr-ft- ${ }^{\circ} \mathrm{F}$, and the two tests were consistent with one another (the thermal conductivity estimates differ by only $2 \%$ ), so it appears there is a definite difference between soil thermal conductivity at the two schools.

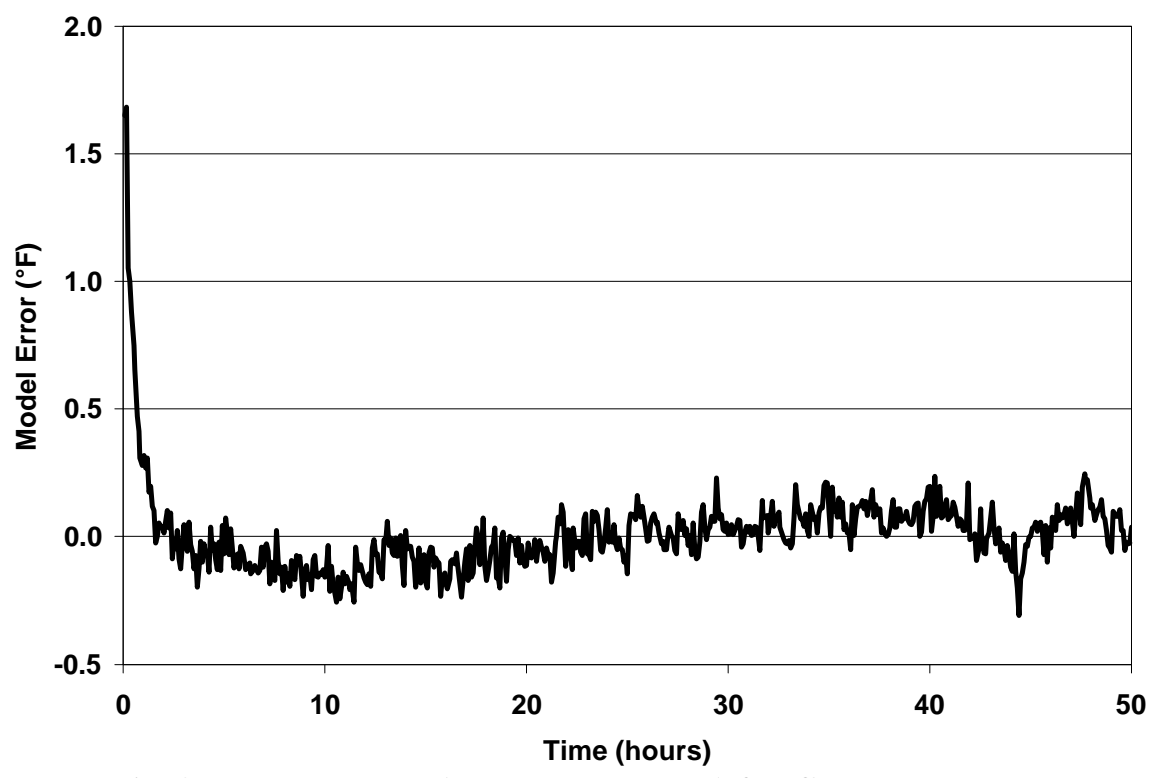

Fig. 3.7. Model error ( $\left.T_{\text {measured }}-T_{\text {calculated }}\right)$ for Campbell Elementary School test \#1. 


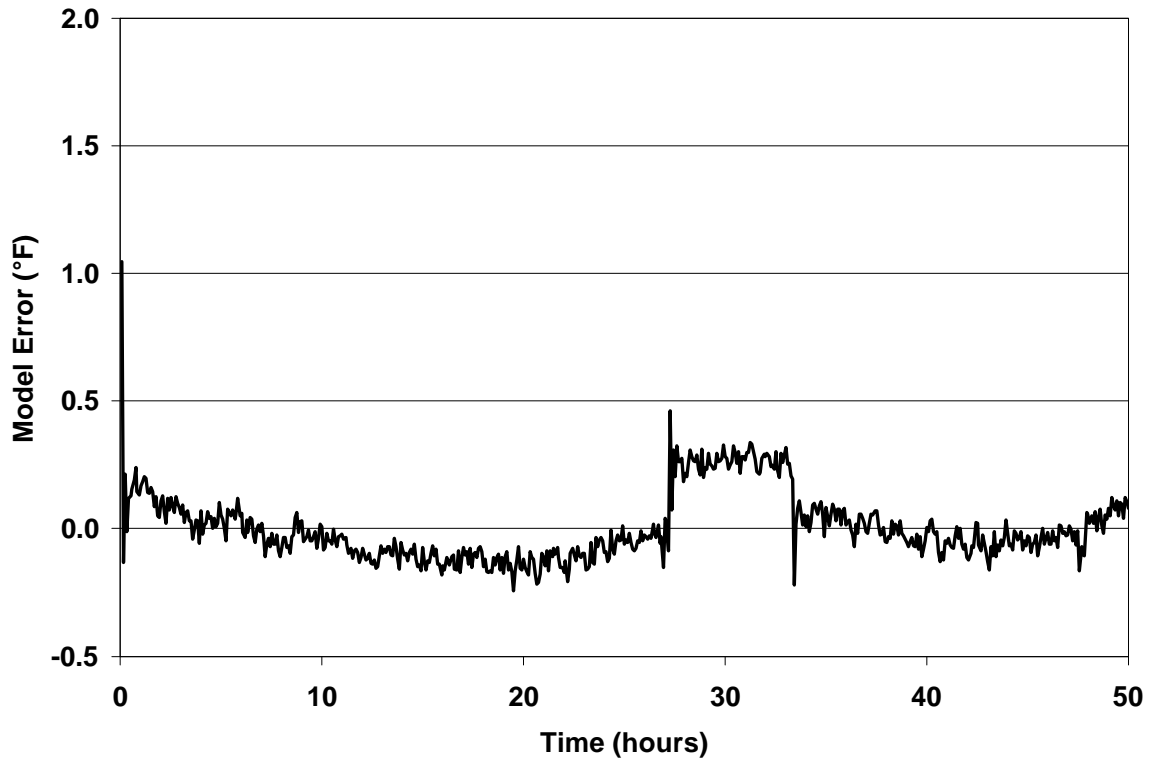

Fig. 3.8. Model error $\left(T_{\text {measured }}-T_{\text {calculated }}\right)$ for Campbell Elementary School test \#2.

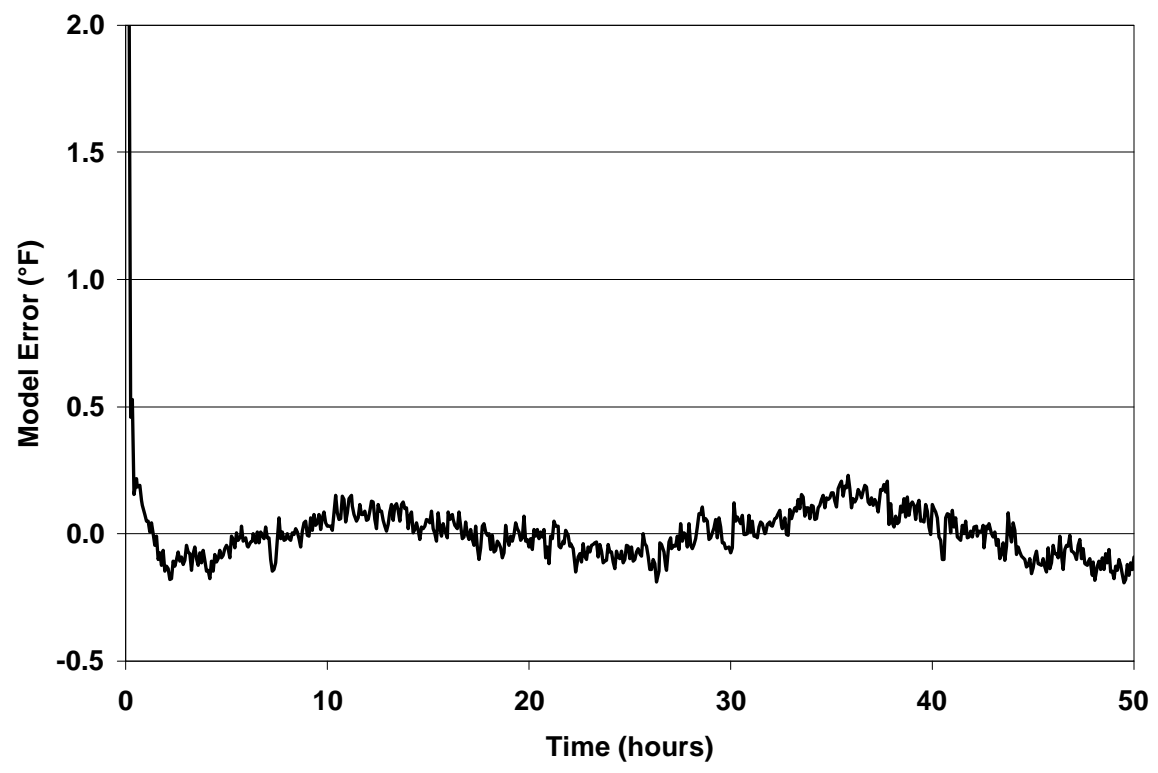

Fig. 3.9. Model error $\left(T_{\text {measured }}-T_{\text {calculated }}\right)$ for Maxey Elementary School test \#1. 
Table 3.2. Results of soil thermal conductivity and borehole resistance estimates from three in situ tests

\begin{tabular}{lccl}
\hline Test designation & $\begin{array}{l}\text { Soil thermal } \\
\text { conductivity } \\
\left(\text { (BTU/hr-ft- }^{\circ} \mathbf{F}\right)\end{array}$ & $\begin{array}{l}\text { Borehole resistance } \\
\left.\text { (hr-ft- }{ }^{\circ} \mathbf{F} / \mathbf{B T U}\right)\end{array}$ & Grout material \\
\hline Maxey & $1.36 \pm .02$ & $0.185 \pm .003$ & Thermal grout 85 \\
Campbell \#1 & $1.20 \pm .04$ & $0.226 \pm .015$ & Soil cuttings \\
Campbell \#2 & $1.19 \pm .03$ & $0.158 \pm .008$ & Fine sand \\
\hline
\end{tabular}

\section{Borehole Resistance}

Although Table 3.2 indicates a definite difference between the borehole resistances measured at each site, it is difficult to say whether the measured borehole resistances correspond to the expected values. For a given U-tube size, borehole resistance is a function of grout thermal conductivity and shank spacing. Spitler (1996) has developed a spreadsheet program that is useful for calculating borehole resistance given shank spacing and grout conductivity. As an example, for a 1-in. SDR-11 U-tube grouted with thermal grout 85 (nominal thermal conductivity of $0.85 \mathrm{Btu} / \mathrm{hr}-\mathrm{ft}-{ }^{\circ} \mathrm{F}$ ), the spreadsheet calculates borehole resistances between 0.176 and 0.313 , depending on the shank spacing assumed. The measured borehole resistance for heat exchanger \#1 at Maxey School does lie within this range, and the fact that it is closer to the lower limit may indicate that the U-tube legs are close to the borehole wall.

Determining the borehole resistance of the heat exchangers grouted with fine sand is more problematic, since the thermal conductivity of sand depends on moisture content. With a nominal value of $1.5 \mathrm{Btu} / \mathrm{hr}-\mathrm{ft}-{ }^{\circ} \mathrm{F}$ for the sand thermal conductivity, the calculated borehole resistance is between 0.139 and .237. The measured resistances for Maxey test \#2 and Campbell test \#2 are both within these limits, and both are closer to the lower limit than the higher one, indicating again that the U-tube legs may be close to the borehole wall.

Heat exchanger \#1 at Campbell school was grouted with soil cuttings. If the grout is assumed to have the same thermal conductivity as the soil, the calculated borehole resistance would lie between 0.151 and 0.248 . The measured borehole resistance does in fact lie between these limits, but certainly, further experiments would have to be conducted to determine whether borehole resistance can be measured reliably with this method.

\subsubsection{Comparison with Other Analysis Techniques}

Table 3.3 compares the thermal conductivity estimates from the three tests using our numerical method with the values obtained using the line source and cylinder source methods. These are 50-h estimates. For the line source method, data prior to $4 \mathrm{~h}$ was ignored. In general the parameter estimates agree well with the estimates using the line source and cylindrical source methods, with differences on the order of only 2 to $3 \%$.

Table 3.3. Thermal conductivity estimates derived by three test methods from 50-h tests

\begin{tabular}{lccc}
\hline $\begin{array}{c}\text { Test } \\
\text { designation }\end{array}$ & $\begin{array}{c}\text { Numerical } \\
\text { method }\end{array}$ & $\begin{array}{c}\text { Line source } \\
\text { method }\end{array}$ & $\begin{array}{c}\text { Cylinder source } \\
\text { method }\end{array}$ \\
\hline Maxey & 1.36 & 1.30 & 1.39 \\
Campbell \#1 & 1.20 & 1.24 & 1.19 \\
Campbell \#2 & 1.19 & 1.18 & 1.22 \\
\hline
\end{tabular}


In addition to comparing the 50-h thermal conductivity estimates, it is also informative to examine plots of sequential estimates from the three methods. These plots show, for every time, the estimate of thermal conductivity obtained by using all the data up to that time. A plot of sequential parameter estimates can indicate whether the method is converging to a particular value, or whether the estimate changes significantly over time. Sequential plots are also useful for estimating how long the data must be collected in order to obtain an accurate parameter estimate.

Figures 3.10 through 3.12 present sequential thermal conductivity estimates for the three experiments from 10 to $50 \mathrm{~h}$, using the one-dimensional numerical method, the line source method, and the cylinder source method. Data prior to the fourth hour was ignored for the line source analysis, and a volumetric heat capacity of $30 \mathrm{Btu} / \mathrm{ft}^{3}-{ }^{\circ} \mathrm{F}$ was assumed for both the one-dimensional numerical method and the cylinder source method. For the two Campbell tests, all three methods converged to within about $5 \%$ of their 50-h values within $24 \mathrm{~h}$ (Figs. 3.10-3.11). This was not the case with the Maxey test, however (Fig. 3.12). Although the estimates from the three methods agree among each other, the plots in Fig. 3.12 suggest that had the measurements continued beyond $50 \mathrm{~h}$, the thermal conductivity estimate at the Maxey site would have continued to rise. One possibility is that there is modest groundwater flow at the site. Conditions such as these, which vary from site to site, make it difficult to make general recommendations as to how long thermal conductivity tests should proceed.

The comparisons indicate that there is little difference between the thermal conductivity estimates derived from our method and the line source method. However, the stable power supply and otherwise good quality of the three data sets tend to mask the usefulness of the method we have developed. Figure 3.13 presents data from a thermal conductivity test carried out at another site. During this test, the field generator developed mechanical problems (personal communication from C. Remund, South Dakota State University, to J. Shonder, ORNL, April 1999). Our conversations with field personnel indicate that short-term voltage spikes are not uncommon, even when line power is used in place of a generator. These spikes can cause significant problems if the line source or cylinder source methods are used to estimate thermal conductivity because both methods assume that the power input is constant. The one-dimensional numerical method we have developed does not assume constant power. Because the model is driven with the field-measured power input, voltage spikes cause very little change in the thermal conductivity estimates.

Figure 3.14 is a plot of sequential thermal conductivity estimates from the data of Fig. 3.13 derived using the line source method, the cylinder source method, and our one-dimensional numerical method. Because the cylinder source method calculates thermal conductivity based only on the measured temperature rise for a particular time, it is much more sensitive to short-term variations in power. For example, between 30 and $33 \mathrm{~h}$ the cylinder source estimate of thermal conductivity drops by almost $10 \%$, owing primarily to fluctuations in the power input. The line source method is somewhat less affected by short-term fluctuations because it uses all of the temperature data up to a given time. Nevertheless, the line source method still assumes constant power input, and this can cause abrupt changes in the thermal conductivity estimate. Our one-dimensional numerical method is the most stable of all because it uses all of the power data and all of the temperature data. As shown in Fig. 3.14, the estimate of thermal conductivity from our method changes by only 1 to $2 \%$ over the entire experiment. 


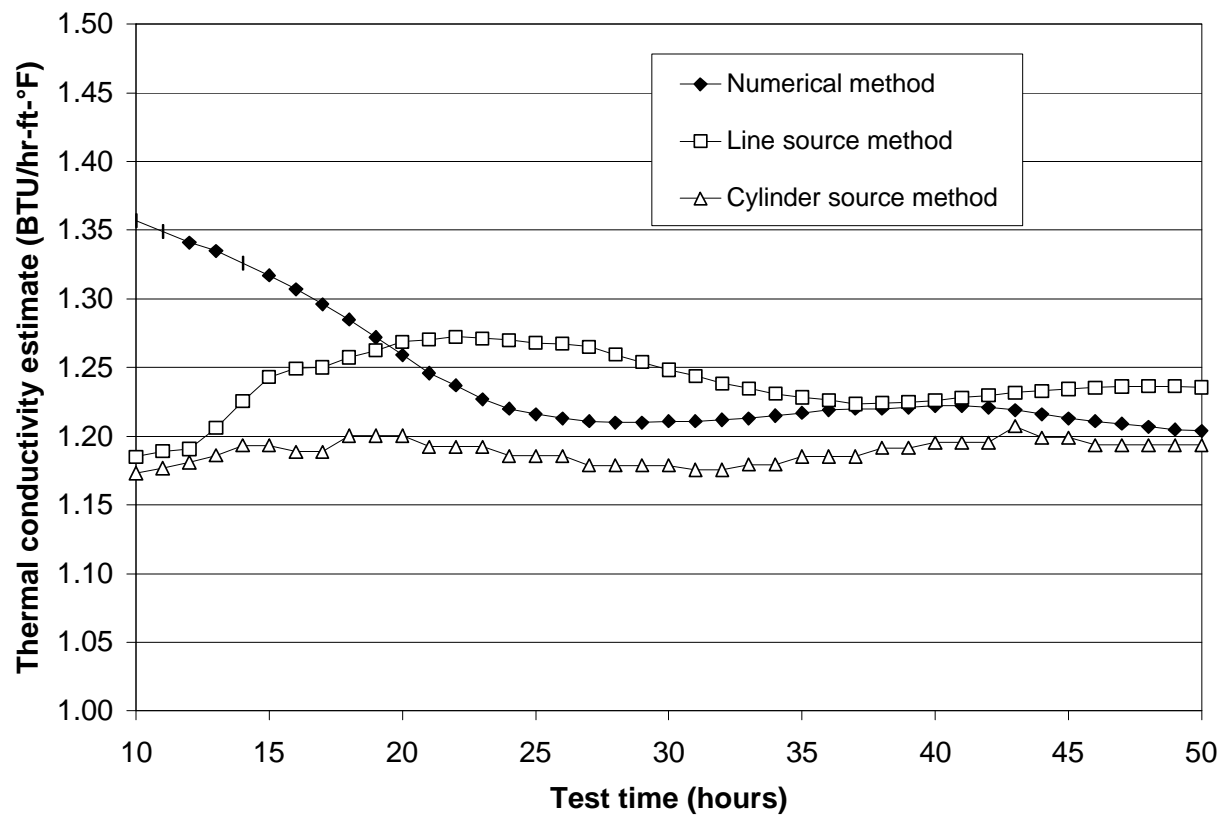

Fig. 3.10. Sequential thermal conductivity estimates, Campbell Elementary School test \#1.

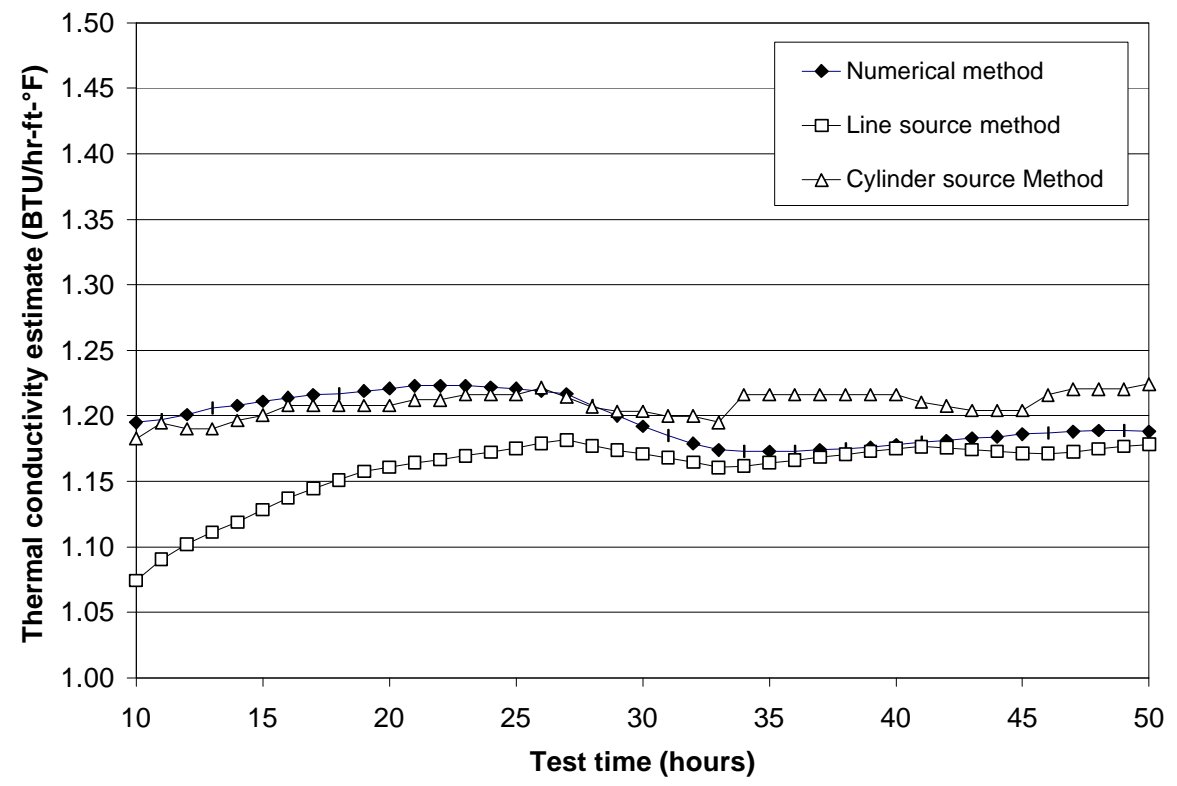

Fig. 3.11. Sequential thermal conductivity estimates, Campbell Elementary School test \#2. 


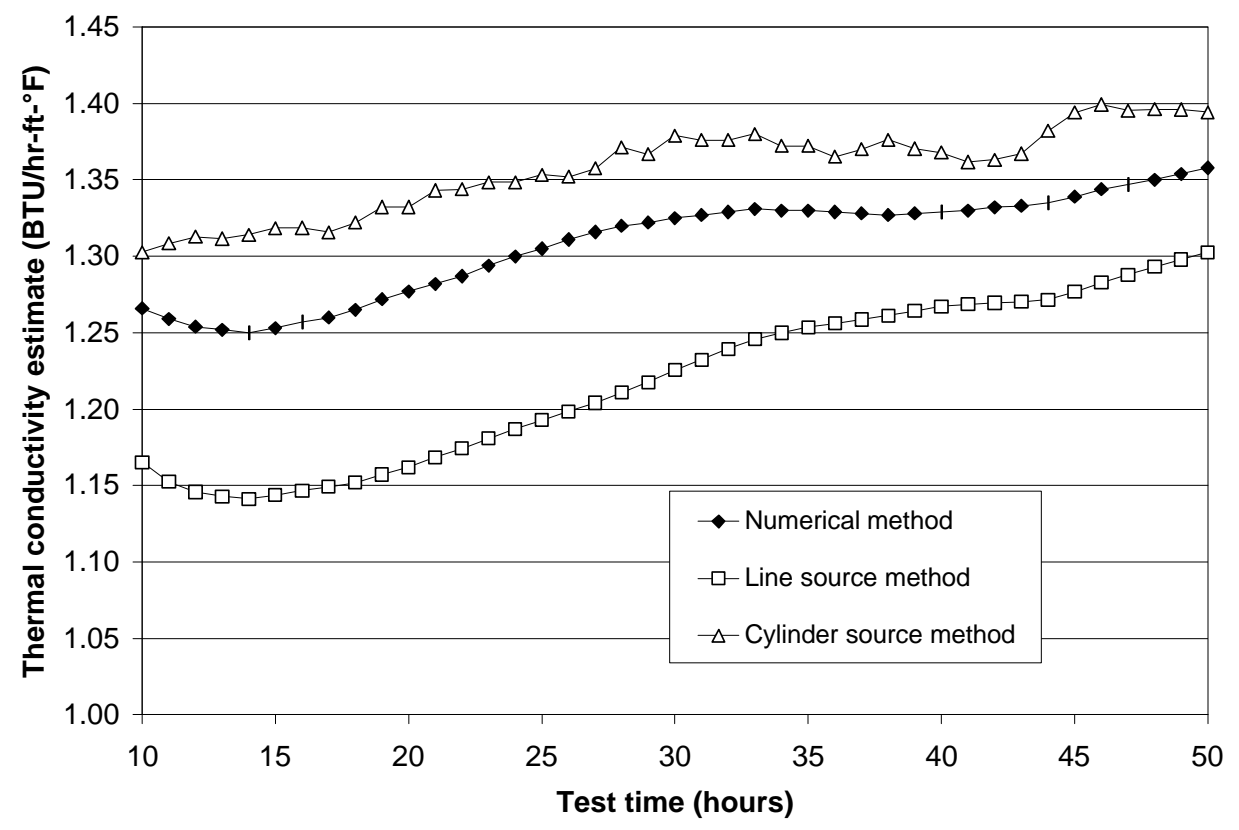

Fig. 3.12. Sequential thermal conductivity estimates, Maxey Elementary School test \#1.

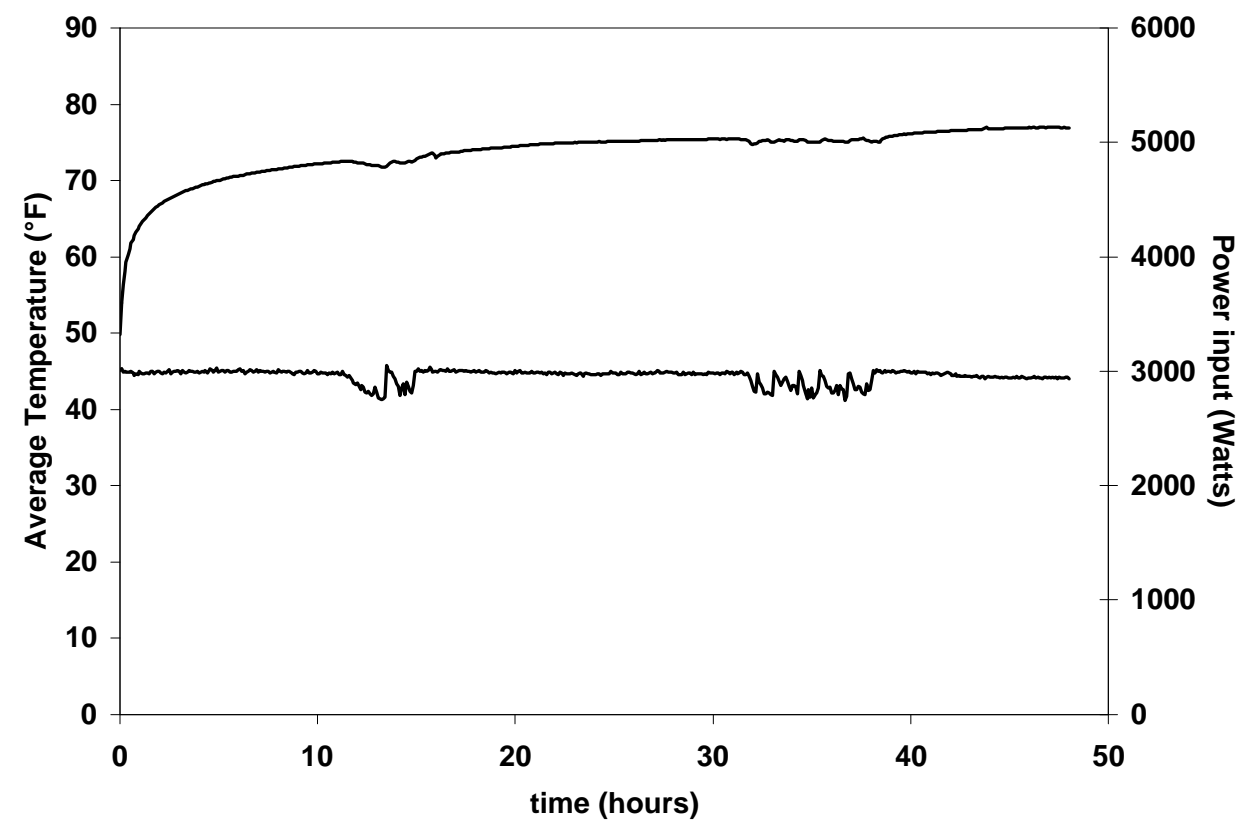

Fig. 3.13. Temperature and power input vs time for a case in which the generator developed mechanical problems. 


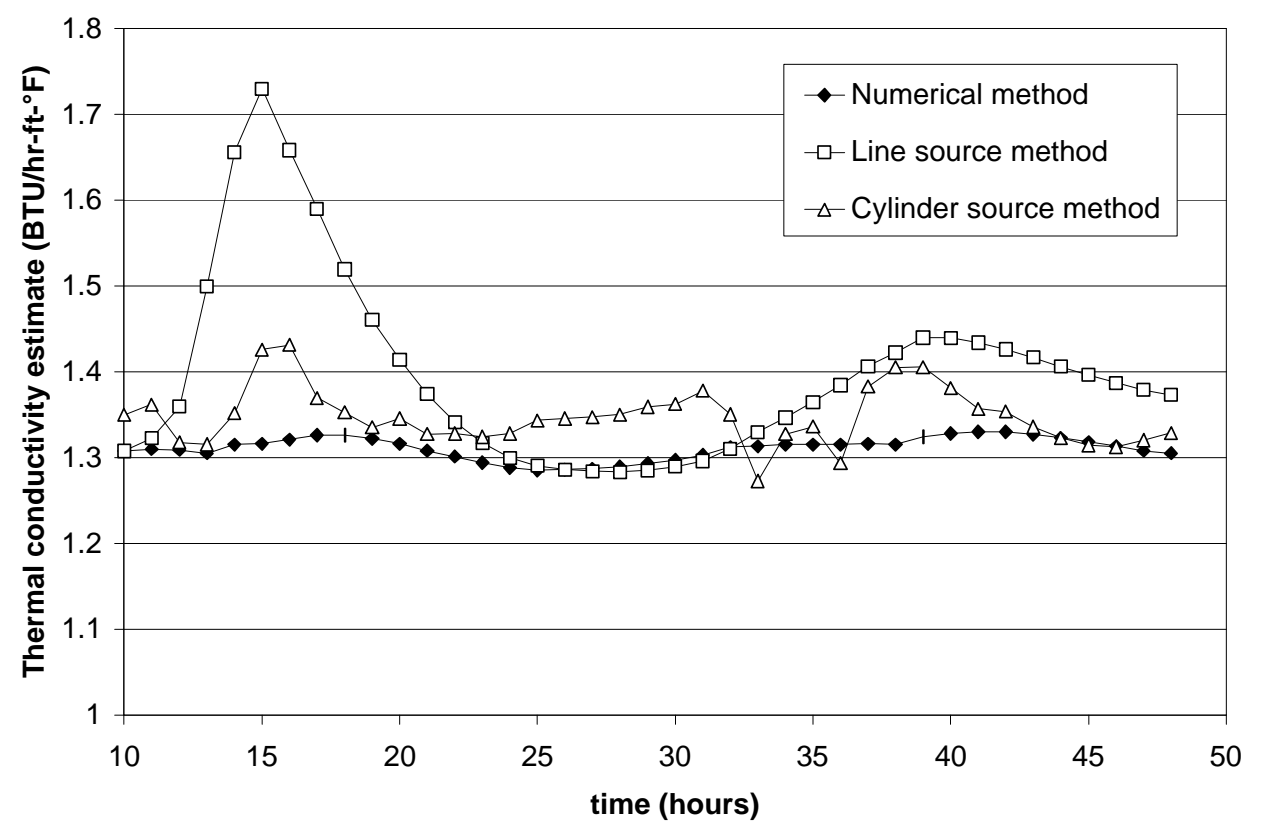

Fig. 3.14. Sequential thermal conductivity estimates from the data of Fig. 3.13.

\subsection{CONCLUSIONS}

The new method of determining soil thermal properties from in situ tests, which is based on a onedimensional numerical heat transfer model, uses parameter estimation techniques to determine soil thermal conductivity and borehole resistance from field-collected data. Tests were needed to validate the method. For this purpose we used test data from an experimental test rig containing sand with a known thermal conductivity. We also conducted tests at schools in Lincoln, Nebraska, that already had one year of data from operating borefields.

For the test rig experiment at Oklahoma State University, in which a U-tube heat exchanger was placed in a medium with independently measured thermal properties, the model's predicted thermal conductivity showed excellent agreement with the measured value after $30 \mathrm{~h}$. After $60 \mathrm{~h}$ the model predicted a slightly higher value of soil thermal conductivity (due perhaps to edge effects associated with the finite volume of the test rig), but the confidence interval still included the measured value.

For the tests in Lincoln, a total of three borehole heat exchangers were installed, two at Campbell Elementary School and one at Maxey Elementary School. The thermal conductivity test at Maxey agreed to within $4 \%$ with a separate thermal conductivity value for the site derived from one year of operating data from the borefield. The two tests at Campbell agreed with each other to within about $2 \%$, but were lower than the values obtained for the Maxey site.

The borehole resistance values of the three heat exchangers were also estimated from the field data. The values measured were within the range of borehole resistances calculated for the grout materials, but because of uncertainty in shank spacing and the actual conductivity of the grout, we recommend that further experiments be performed to determine the reliability, accuracy, and repeatability of the borehole resistance measurements. 
The thermal conductivity measurements from our method agree with the values obtained from the line source and cylinder source methods. This is to be expected because the power input was relatively stable during the course of the three experiments. Analysis of a separate data set showed that thermal conductivity estimates from the line source and cylinder source methods are significantly affected by variations in power input, while the thermal conductivity estimate from the method we have developed varied by only about $1 \%$ over the course of the experiment. 


\section{GPM SOFTWARE TUTORIAL}

\subsection{INTRODUCTION}

This chapter provides an introduction to the features of the GPM program, including the options available in the main input menu and the information that is provided in the output window. Numerous illustrations show what the user will see on the computer screen.

\subsection{MAIN MENU}

The main menu, used for input, comes up automatically following an initial 3-s identification screen. A sample of the main page is shown in Fig. 4.1.

In the example shown in Fig. 4.1, the unit selection is the default value, which is the English unit system. The experimental data file and the output file are shown in the file name windows. The experimental data file name and/or the output file name can be manually typed into the appropriate file window.

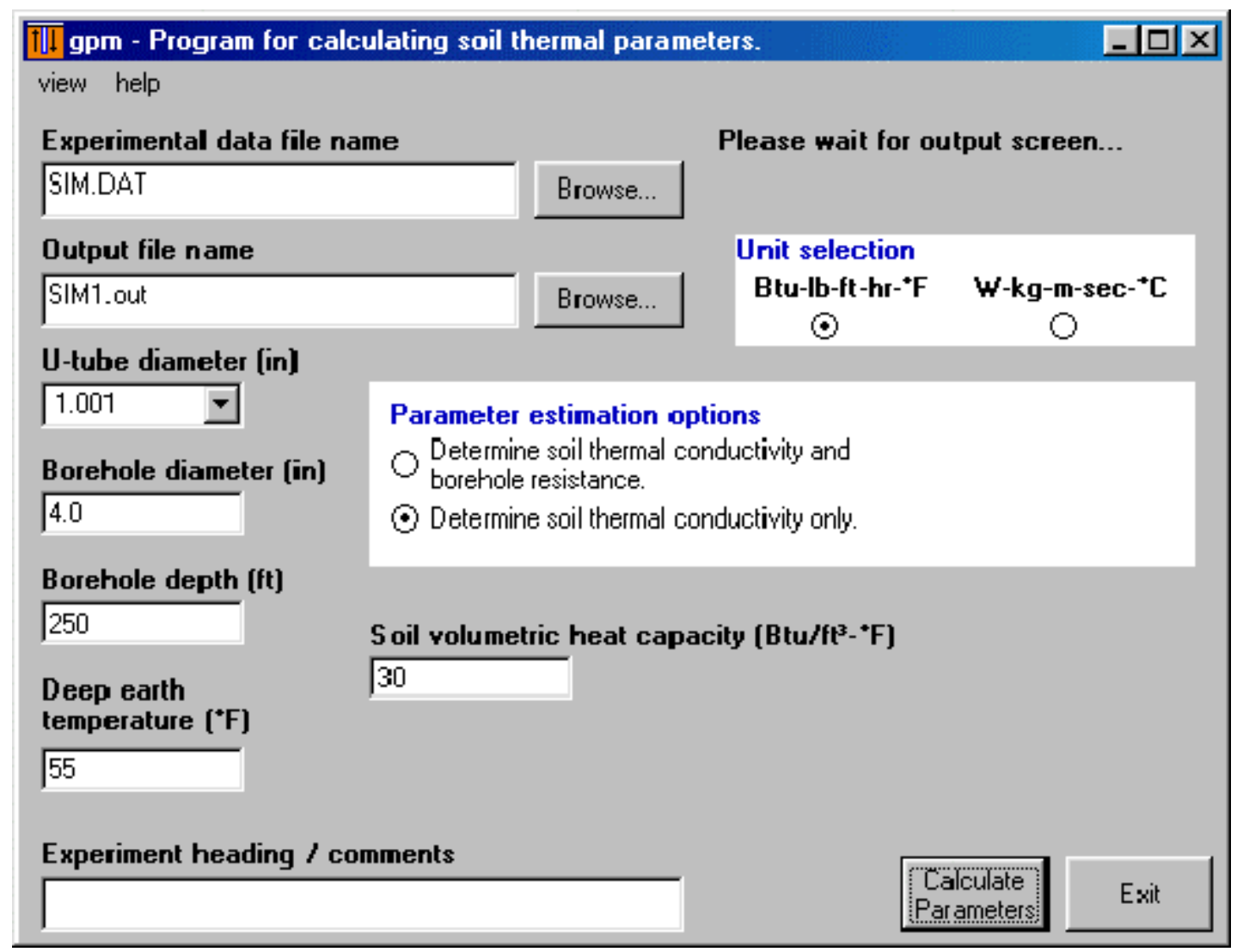

Fig. 4.1. The main data input screen in GPM. 
Alternatively, the user can select the desired experimental data file or output file, as applicable, by using the Browse button. A file dialog box appears when Browse is selected. A sample of the file dialog box is shown Fig. 4.2. To make a selection, the user simply double-clicks the appropriate directory, if the desired directory is not already displayed. Following this, the user double-clicks the appropriate file name.

If a disk drive other than the one containing gpm.exe is desired, this can be selected in the upper right hand corner of the file dialog box. Similarly, if an extension other than the default .out is desired, the appropriate selection can be made in the lower lefthand corner.

The following sections explain the input features on the main menu.

\section{Experimental data file name}

The experimental data file, containing the measurements from the borehole test, is provided by the user. The data configuration must be three columns: time, average (of the inlet and outlet) water temperature, and heat flux. Assuming English units are selected, the time should be in hours, the temperature in degrees Fahrenheit, and the heat input in watts. (The heat input unit is particularly important to note because it is not consistent with the English units.) The three columns may be separated by spaces or tab delimiters. The time steps, as given in the first column of the experimental data file, must be uniform.

The experimental data file name will be loaded automatically if a previously saved output file is used and reloaded. In this case, the user should verify the path listed to ensure that it is still valid. This is especially important when using a file from another user's machine, since the file may have been saved in a different directory structure on the other machine which does not exist on the user's machine.

\section{Output file name}

The beginning of the output file contains all of the information entered by the user on the main menu (date, time, file names and all other user selections). It also includes all of the output from the parameter estimation program, including everything displayed in the output window. The output data file name is chosen by the user. It is typically given a out file name extension but can be saved under any name.

The output file name can either be selected from the existing directory structure, if an output file already exists, or entered manually. If it is desirable to save the file in a directory other than the GPM program directory, that directory should be entered in the Output file name window on the main menu. 
If a new output file is being developed, the applicable experimental data file can be located using the Browse button next to the experimental data file line. Selecting this button automatically opens the file dialog box and allows the user to select the appropriate file by double-clicking on the desired directory and file name.

\section{Unit selection}

Although English units are by far the most common selection, and the system default, an option is provided for metric units. The user is automatically prompted to input data in the data boxes (described below) according to the unit system selected. The user must exercise care regardless of the system selected because the units designated for data input are not consistent; for example, data input in the English system uses both inches and feet. (See Fig. 4.1.)

\section{Parameter estimation options}

The main menu provides two options for analyzing borehole temperature data. These are found in the Parameter estimation options box. The available options are "Determine soil thermal conductivity and borehole resistance" (grout-soil model) and "Determine soil thermal conductivity" (homogeneous soil model).

\section{Determine soil thermal conductivity and borehole} resistance. This option provides two thermal parameter estimates. One parameter is soil thermal conductivity, and the other is borehole resistance. In addition, the deep earth temperature is estimated. For this model, the borehole grout is assumed to be a hollow cylinder of outer radius equal to the borehole radius and inner radius equal to the effective U-tube radius, $r_{i}$ (Fig. 4.3). (For more discussion of $r_{i}$ see the discussion of the Utube diameter below.) Borehole resistance is simply the reciprocal of the heat transfer coefficient for a unit thickness of material, according to the equation

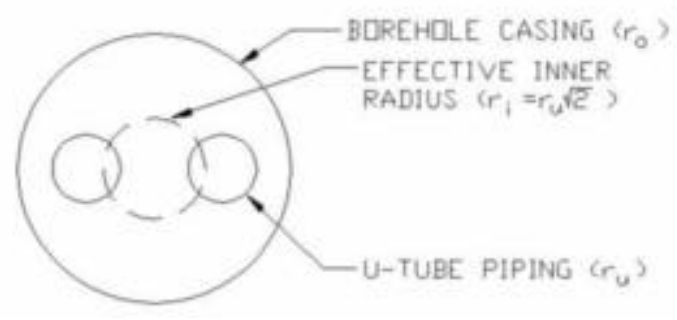

Fig. 4.3. Cross-sectional view of borehole showing dimensions.

$$
\text { Borehole Resistance }=\frac{1}{2 \pi k_{g}} \ln \left(\frac{r_{0}}{r_{i}}\right),
$$

where $r_{o}$ is the outer radius of the grout (i.e., the borehole radius), $r_{i}$ is the effective inner radius (i.e., the actual outside U-tube radius multiplied by $\sqrt{2}$ ) and $k_{g}$ is the thermal conductivity of the grout. The soil in this case is considered as a separate region, which is from $r_{o}$ to a thermally large radius.

Determine soil thermal conductivity only. This is the simplest option and returns the soil thermal conductivity and the deep earth temperature, both with confidence regions. The model for this option assumes that the thermal properties of the grout are the same as that of the soil and lumps both materials into one region.

\section{U-tube diameter}

The U-tube diameter is the diameter of the inner tube of the borehole in the units shown on the caption for the data box. (English units are inches, and metric units are centimeters.) Standard sizes may be pulled down from a menu inside the data entry box. When standard U-tube diameters of $3 / 4,1$, $1 \frac{1}{4}, 1 \frac{1}{2}$, or 2 in. are selected, these values are replaced automatically by the actual outer-diameter dimensions of $1.050,1.315,1.660,1.900$, or 2.375 in., respectively. One-half of these diameters is the 
radius denoted $r_{u}$, which GPM then multiplies by $\sqrt{2}$ to simulate the inlet and outlet pipes. This gives the effective radius of $r_{i}=(2)^{1 / 2} r_{u}$.

\section{Borehole diameter}

The borehole diameter is the diameter of the outer borehole in the units (inches for English units) shown on the caption for the data box.

\section{Borehole depth}

The borehole depth is the depth of the borehole in the units (feet for English units) shown on the caption for the data box.

\section{Deep earth temperature}

The deep earth temperature normally entered is the starting temperature of the water exiting the borehole. It is an estimated quantity in GPM, but a realistic value should be entered here. Because it is used as prior information by the program, its value will have a small effect upon the final estimate of the deep earth temperature and a much smaller effect on the estimates of the thermal parameters.

\section{Experiment heading/comments}

This optional entry item allows the user to keep notes on particular items of interest having to do with an experiment or an analysis of an experiment. Since more than one analysis can be performed on one experiment, this can be used to distinguish between analyses.

\section{Soil volumetric heat capacity}

The default entry for soil volumetric heat capacity - $30 \mathrm{Btu} / \mathrm{ft}^{3}-{ }^{\circ} \mathrm{F}$ in the English system — is typical for most soils. The range of volumetric heat capacity does not vary much around this. Even more important, the thermal conductivity estimates are relatively insensitive to the value of the volumetric heat capacity. If a value is known for a particular soil, however, it can be entered here. When a grout layer is included, a separate value for the grout can be entered.

\section{View}

A pull-down menu allows the user to choose whether or not the DOS shell program is to be viewed. The parameter estimation calculations are actually performed by a separate program called sub.exe that is called up by GPM. The user can view this program while it is running if desired. The default condition is to allow the program to run in a minimized state that is not visible to the user. A run-time indication is displayed in order to show the user that the calculations are being performed.

\section{Calculate parameters}

Once the Calculate Parameters button is selected, the parameter estimation calculations will begin. At this time, the output information is saved in the output file. If an output file of the name selected has already been saved by the user, a warning window will appear to ensure that the user realizes that the previous file will be overwritten. Following this, the calculations will begin, and the run-time indication will begin to display the number of seconds of run time. The output screen will automatically appear when the calculations are completed.

\section{Exit}

If the exit button is depressed, the program will stop. A user who wishes to continue using GPM will have to restart the program. 


\subsection{OUTPUT WINDOW}

The output window contains all of the information contained in the output file. The window has four tab selection options, labeled Tabular Output, Residuals, Sensitivity Coef., and Sequential Est. (see Fig. 4.4). The output presented in each of these windows is summarized below.

\section{Tabular output}

The tabular output window is the initial window that appears upon completion of the parameter estimation calculations. It provides the requested calculated parameter values in bold print at the top of a scrollable text screen. The remainder of the screen contains the contents of the entire output file, including input data, confidence regions, residuals, sequential parameter estimates, and sensitivity coefficients.

\section{Residual plot}

The residual plot is a graphical plot of the residuals vs time. The residuals are defined as the measured temperature values minus the calculated temperatures from the mathematical model. A plot of the residuals is valuable because this graph can be examined for a characteristic signature. Ideally, the residual graph should be purely random, reflecting random temperature measurement errors.

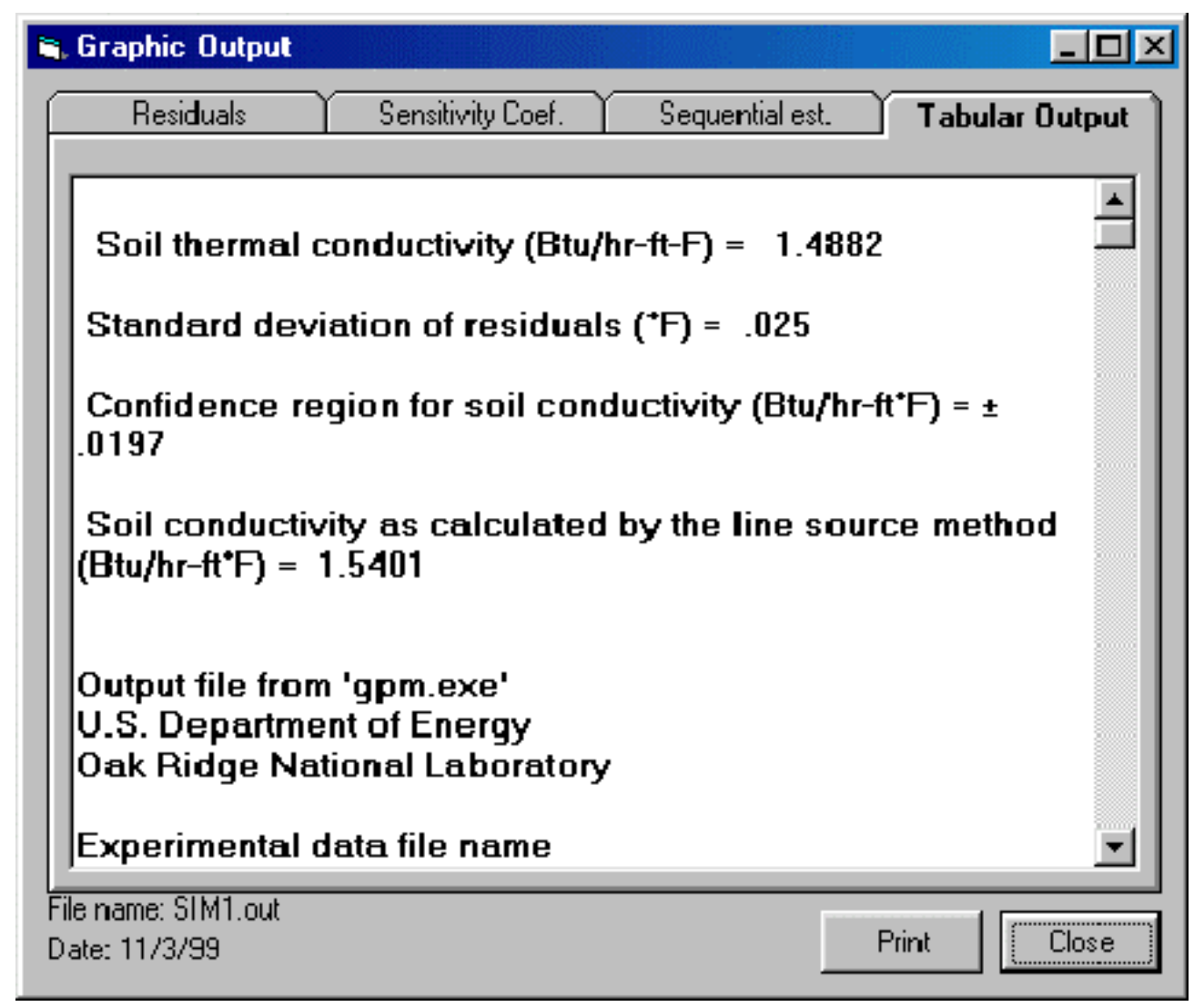

Fig. 4.4. The GPM output window. This screen, showing tabular output, is the output window that appears first. 


\section{Sensitivity coefficient plot}

The sensitivity coefficient plot is a graphical representation of the modified sensitivity coefficients as functions of time. There are as many sensitivity coefficients as there are thermal parameters to be estimated. The sensitivity coefficient of the deep earth temperature is simply a constant with time and is not shown. The modified sensitivity coefficient for the soil conductivity is the soil conductivity multiplied by the partial derivative of the calculated temperature at $r_{i}$ with respect to the soil conductivity. It has units of temperature and can be compared with the temperature rise.

\section{Sequential parameter plot}

The sequential parameter plot is a graphical representation of the sequential parameters as functions of time. There are as many sequential parameters to be plotted as there are thermal conductivities to be estimated. The sequential values are the estimated parameters using the experimental data only up to the corresponding time of the individual sequential parameter value. In a satisfactory analysis the sequential parameter estimates should be nearly constant for the last half of the duration of the experiment. If there is even a small drift upward or downward, an imperfection in the model or inaccuracies in the data (or both) are indicated.

Any of the above screens can be printed on the default printer for the machine in use simply by selecting the Print button. When printed, the data or plots appear as they do on the screen except that the tabs and buttons are not shown. 


\section{CONCLUSIONS}

A new method has been developed for the calculation of effective soil formation thermal properties from short-term in situ field tests. The model underlying the method is one-dimensional radial heat conduction in a composite medium; the conduction problem is discretized using finite difference techniques and solved using the Crank-Nicolson scheme. The new method has been incorporated into The Geothermal Properties Measurement (GPM) model, a stand-alone computer program for the Windows 95/98 operating system.

In a short-term in situ field test, water is heated at a measured rate and pumped through a U-tube heat exchanger. The measurement technique we have developed requires interval data on the heat input to the heat exchanger and the average temperature of the water in the heat exchanger. The fieldmeasured heat input is used to drive the numerical heat-transfer model of the soil and grout. The temperature at the centerline of the numerical model is compared to the field-monitored average water temperature, and the thermal properties of the model (deep earth temperature, thermal conductivity and thermal diffusivity of both the soil and the grout, etc.) are varied until the model's predictions match the field-monitored average water temperatures in a least-squares sense. All of these calculations are carried out by the software, which then reports the thermal properties and an estimate of their accuracy given the accuracy of the data.

The new method offers several advantages over the line source and cylinder source methods currently used to analyze data from short-term in situ field tests. First, unlike the line and cylinder source methods, the accuracy of our numerical method is not affected by short-term variations in power input to the heat exchanger. Second, our numerical method is more accurate at early times, and therefore does not require early data to be discarded, as do the line and cylinder source methods. Finally, unlike the simple curve-fitting techniques used with the line and cylinder source methods, our method provides a qualitative estimate of the accuracy of the thermal properties it reports.

The GPM software has been validated with tests on a dedicated thermal conductivity test rig and with data from field tests carried out in Lincoln, Nebraska. 


\section{REFERENCES}

Alifanov, O. M. 1994. Inverse Heat Transfer Problems. New York: Springer-Verlag.

Austin, W. A. 1998. "Development of an In-Situ System for Measuring Ground Thermal Properties." M.S. thesis, Oklahoma State University.

Bard, Y. 1974. Nonlinear Parameter Estimation. New York: Academic Press.

Beck, J. V. 1999. User's Manual for IHCP1D: Program for Calculating Surface Flux from Transient Temperatures inside Solids. Okemos, Mich.: Beck Engineering Consultants Co.

Beck, J. V., and K. J. Arnold. 1977. Parameter Estimation in Science and Engineering. New York: John Wiley.

Beck, J. V., B. Blackwell, and C. R. St. Clair. 1985. Inverse Heat Conduction: Ill-Posed Problems. New York: John Wiley.

Beck, J. V., K. D. Cole, A. Haji-Sheikh, and B. Litkouhi. 1992. Heat Conduction Using Green's Functions. Washington, D.C.: Hemisphere Publishing Co.

Beck, J. V., and J. A. Shonder. 1998. "A Parameter Estimation Technique for Determining Soil Thermal Properties in the Design of Heat Exchangers for Geothermal Heat Pumps." In Proceedings of the ASME Heat Transfer Division, 3:221-40.

Bevington, P. R. 1969. Data Reduction and Error Analysis for the Physical Sciences. New York: McGraw-Hill.

Bose, J. E., J. D. Parker, and F. C. McQuiston. 1985. Design/Data Manual for Closed-Loop GroundCoupled Heat Pump Systems. Atlanta: American Society of Heating, Refrigerating and Airconditioning Engineers.

Carslaw, H. S., and J. C. Jaeger. 1947. Conduction of Heat in Solids. Oxford: Claremore Press.

Deerman, J. D., and S. P. Kavanaugh. 1991. "Simulation of Vertical U-Tube Ground-Coupled Heat Pump Systems Using the Cylindrical Heat Source Solution." ASHRAE Transactions 97, Pt. 1: 287-95.

Draper, N. R., and H. Smith. 1966. Applied Regression Analysis. New York: John Wiley.

Eskilson, P. 1987. Thermal Analysis of Heat Extraction Boreholes. Lund, Sweden: Dept. of Mathematical Physics, University of Lund.

Hellstrom, G. 1991. Ground Heat Storage. Lund, Sweden: Dept. of Mathematical Physics, University of Lund.

Ingersoll, L. R., O. J. Zobel, and A. C. Ingersoll. 1954. Heat Conduction with Engineering, Geological and Other Applications. New York: McGraw-Hill.

Kavanaugh, S., and K. Rafferty, K. 1997. Ground-Source Heat Pumps: Design of Geothermal Systems for Commercial and Institutional Buildings. Atlanta: American Society of Heating, Refrigerating and Air-conditioning Engineers.

Morgensen, P. 1983. "Fluid to Duct Wall Heat Transfer in Duct System Heat Storages." In Proceedings of the International Conference on Subsurface Heat Storage in Theory and Practice, Swedish Council for Building Research, June 6-8. 
Rottmayer, S., W. A. Beckmann, and J. W. Mitchell. 1997. "Simulation of a Single Vertical U-Tube Ground Heat Exchanger in an Infinite Medium.” ASHRAE Transactions 103, Pt. 2: 651-59.

Shonder, J. A., and J. V. Beck. 1999. "Determining Effective Soil Formation Thermal Properties from Field Data Using a Parameter Estimation Technique.” ASHRAE Transactions 105, Pt. 1: 458-66.

Spitler, J. D. 1996. "Borehole Resistance Calculator." Excel spreadsheet distributed with GLHEPROWin. Available from the International Ground Source Heat Pump Association (IGSHPA), Stillwater, Oklahoma. See http://www.igshpa.okstate.edu/Publications/Catalog/1998/Software.html. 